\title{
The Folk Theorem of Decreasing Effectiveness of Monetary Policy: What Do the Data Say?
}

\section{Ugo Panizza, The Graduate Institute, Geneva and CEPR \\ Charles Wyplosz, The Graduate Institute, Geneva and CEPR}

It is increasingly claimed that unconventional monetary policies are subject to decreasing effectiveness in supporting growth and raising the inflation rate. There are good reasons to believe that the effects of further asset purchases by central banks and of moving the interest rate deeper in negative territory progressively decline. But has it been happening? This paper attempts to provide an answer. Looking at the Eurozone, the UK, the US and Japan, it uses different approaches (local projection and Bayesian VAR) on different sub-samples. The evidence is mixed. Policy interventions proxied by the shadow policy rate seem to be subject to the decreasing effectiveness hypothesis. However, this is not the case for QE announcements.

Keywords: unconventional monetary policy, zero lower bound, shadow policy rate

JEL: E52, E58

\section{Introduction}

After several years of experimentation, a growing number of observers are convinced that unconventional monetary policies are becoming increasingly less efficient (see, e.g., Goodhart and Ashworth, 2012; Krishnamurthy and VissingJorgensen, 2013; Roubini, 2014; Blanchard, 2016a; Oakley, 2016). Central bankers, on the other hand, generally consider that these policies work well and eventually deliver what they are designed for (Draghi, 2016; Gagnon et al., 2016), although

\footnotetext{
${ }^{1}$ We are most grateful to Tomasz Wieladek for having generously shared data and for help with coding. We also wish to thank the National Institute of Economic and Social Research and Kiyohiko Nishimura for providing data. We acknowledge useful comments by Jesper Lindé, Lawrence Ball, Joe Gagnon and Athanasios Orphanides.
} 
the lags may be much longer than with traditional monetary policy (Engen et al., 2015). Former central bankers are less sanguine, though (Bernanke, 2016; Ueda, 2012)2. A poll of British-based economists (Armstrong et al., 2015) shows that opinions on the issue are about equally split. This paper attempts to determine which view is backed by (admittedly short) data.

Nearly ten years after the Global Financial Crisis, growth remains subdued and inflation is significantly below target in most advanced economies. It may be that this state of affairs is unrelated to monetary policy. Slow growth is sometimes justified by the secular stagnation hypothesis or to on-going widespread deleveraging, while low inflation is related to a possibly flatter Phillips curve. Responses to these possibilities do not belong to central banks. Yet, the central banks of the US, Japan, the UK, and the Eurozone (and others as well) are actively engaged in trying to support growth and raise inflation with unconventional policies. It matters greatly whether they have the tools to achieve these objectives. In the presence of decreasing effectiveness, they would have to act increasingly aggressively (Orphanides and Wieland, 2000). Ominously, however, if economic agents think that unconventional polices do not work, inflation expectations could decrease, as they have in Japan. In that case, the task of central banks could become hopeless.

Skeptics argue that unconventional policies have drawbacks. They fear the mispricing of risk, the scarcity of safe assets and, more generally, distortions created by interest rates that remain too low for too long. While central banks seem to believe that the risks are small and the effects large, skeptics take the view that the balance between costs and benefits - or between risk and returns - is increasingly tilting against unconventional policies. This view implies that fiscal policies should take over. Given the high indebtedness of many governments in advanced countries, this means shifting from one series of drawbacks to another one. An often mentioned way-out is helicopter money, fiscal expansions financed by money creation.

For these reasons, it is helpful to assess the decreasing effectiveness hypothesis. While the sample size is limited, there are good reasons to attempt an early evaluation. This is a live issue which is also key for assessing the potential role to be played by fiscal policies. Moreover, unconventional policies are not meant to be pursued for years onward. They have already stopped in the US, where the issue is when and how to exit. This means that the sample size is unlikely to increase much further.

Given the short sample horizon, we need to use monthly data, which inevitably restricts the range of variables that can be examined (for instance, in the case of the

\footnotetext{
${ }^{2}$ Bernanke states that "there are signs that monetary policy in the United States and other industrial countries is reaching its limits."
} 
Eurozone and Japan we need to use industrial production instead of GDP). Moreover, macroeconomic phenomena are slow. Standard monetary policy, for instance, is understood to affect the real economy after several quarters and unconventional policies may take longer to make a difference (Engen et al., 2015). It follows that monthly data may be more noisy than desirable. This explains why most studies so far have looked at the effects of unconventional policies on financial markets, which react fast. These studies have detected strong effects, but that is only the first step in actually fostering growth and raising inflation. We, instead, follow Weale and Wieladek (2015), Garcia Pascual and Wieladek (2016), and Haldane et al. (2016) and directly examine the impact of unconventional policies on growth and inflation. We contribute to the literature by providing a direct test for the decreasing hypothesis and experimenting with alternative measures of unconventional policies. We finds some evidence of decreasing effectiveness although the statistical significance of these results is limited, marred as it is by the short time span under study.

The paper is organized as follows. The next section briefly reviews the channels of effects of unconventional policies, and informally provides arguments for the decreasing policy effectiveness hypothesis. Section 3 summarizes recent empirical research designed to measure the effects of unconventional policies and explains our own strategy. Section 4 presents a battery of tests designed to determine the empirical validity of the hypothesis in the case of the US, Japan, the UK, and the Eurozone. The last section concludes.

\section{Channels of Effects and the Decreasing Effectiveness Hypothesis}

A growing body of literature describes and evaluates how unconventional monetary policies affect the economy and identifies the potential channels though which these policies operate ${ }^{3}$. This section examines reasons why decreasing effectiveness could set in. It follows the traditional analysis of standard monetary policy that considers the direct interest rate channel, the confidence channel, the portfolio balance channel, the bank credit channel, the sovereign credit risk channel, and the exchange rate channel.

Decreasing effectiveness means that the effect of the relevant instrument declines as it is used more intensively. It is an assertion that the relationship $y=f(x, Z)$ between the instrument $(x)$ and the sought-after effect $(y)$ is not

\footnotetext{
3 The earlier literature focused on quantitative easing. Contributions include Bernanke et al. (2004) and Krishnamurthy and Vissing-Jorgensen (2013). Recent reviews include Borio and Zabai (2016), Fratzscher el al. (2014), Santor and Suchanek (2016), and World Bank (2015).
} 
necessarily linear and, at any rate, becomes concave downward when $x$ increases sufficiently, that is $\partial f / \partial x>0$ for low (normal) values of $x$ and $\partial^{2} f / \partial x^{2}<0$, at least beyond some threshold ${ }^{4}$. In the present case, we will estimate $\partial f / \partial x$ over different samples and check whether the instrument loses potency over time. We do not attempt to identify the channels involved, leaving it for further work.

\subsection{Non-standard monetary policies}

Unconventional monetary policies start when the policy interest rate approaches the Zero Lower Bound (ZLB). Having reached the ZLB, a number of central banks have looked for other ways to lift the inflation rate toward its target and promote growth.

The two main instruments have been Quantitative Easing (QE) and negative interest rates. Central banks have supplemented these instruments with forward guidance, essentially committing to keep the policy rate at the ZLB or below for a long period of time and announcing a precise schedule of asset purchases spread over several quarters. We look at these two main instruments and their channels of transmission and ask whether there exist plausible reasons for entertaining the presence of decreasing effectiveness.

\section{Negative interest rates}

Negative interest rates are often seen as a straightforward extension of standard policy, whereby there is no reason to see zero as particularly meaningful. In addition, what matters for economic activity is the real interest rate, which can be and has been negative independently of the level of the nominal rate. In fact, negative nominal interest rates are all but straightforward (Coeuré, 2016).

Cash money bears zero interest, which is why it is presented as a dominated asset. The usual explanation of why money exists at all is that it yields an implicit positive return in the form of transaction services. It follows that any asset that can be freely exchanged for money must offer a higher, i.e. a positive yield. Since central banks normally set the interest rate by intervening on very short-term maturity assets, they should not be able to bring the policy rate below zero. We now know that this conclusion is incorrect. The reason is that cash is costly to hold in large amounts because of storage and insurance costs. These costs, however, are finite and not very large. The implication is that there is a limit to how negative interest rates can be: the zero lower bound can be breached, but there exist an

\footnotetext{
${ }^{4}$ In this example, an increase of $x$ is meant to capture an expansionary unconventional monetary policy. If the instrument is the policy interest rate and the outcome is GDP growth or inflation, we should write $\partial f / \partial x<0$ for normal values of $x$ and $\partial^{2} f / \partial x^{2}<0$, at least below some threshold.
} 
effective lower bound (ELB). The position of this bound will remain unknown until it is breached. Even so, it is likely to differ from country to country depending on the structure of the banking system, taxation, regulation, etc.

\section{Quantitative easing}

Quantitative easing (QE) includes many procedures and official names ${ }^{5}$. The defining purpose is to inject, without sterilization, large amounts of liquidity by buying assets held by banks or by investors according to a preannounced purchase program. The assets usually are chosen to be safe, normally Treasury debt. Central

Figure 1. The Fed's balance sheet and CPI, January $2003=100$
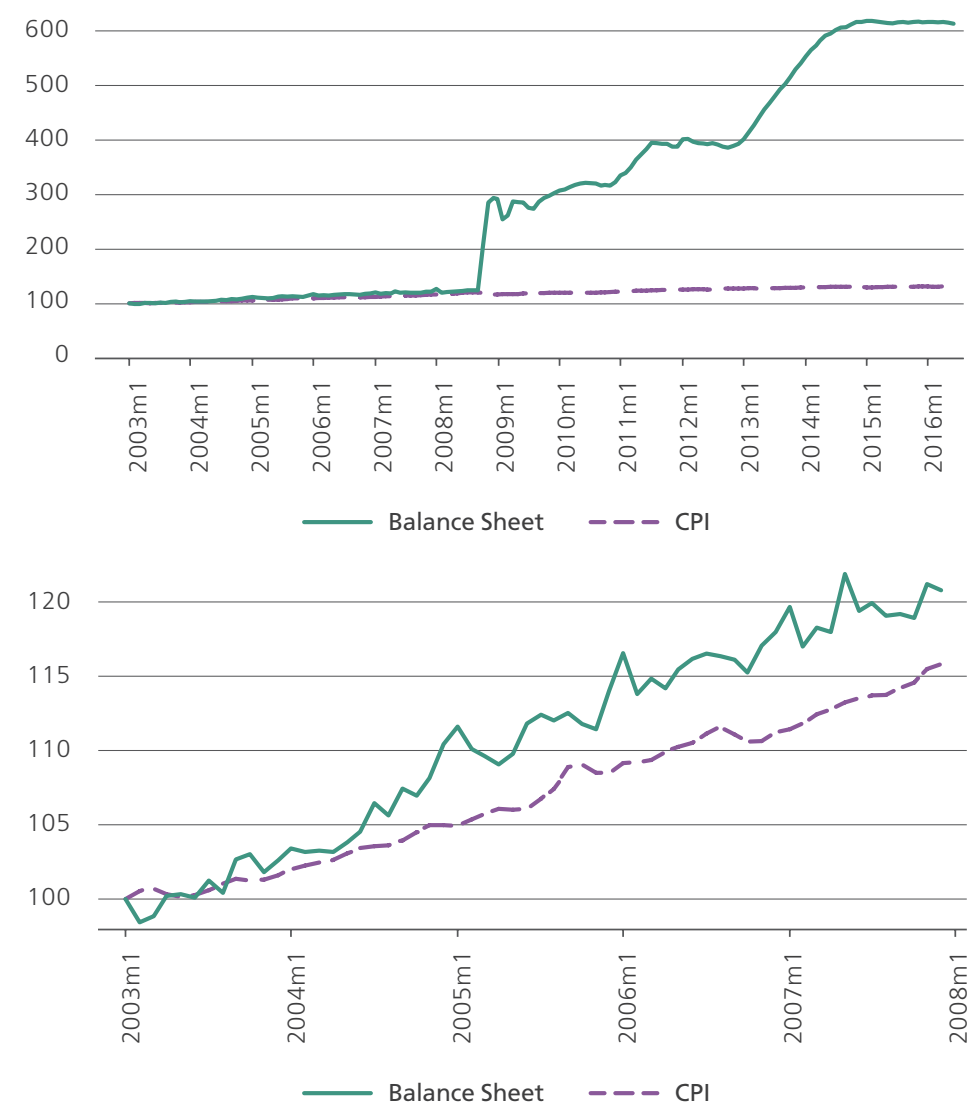

Source: FRED, Federal Reserve Bank of Saint Louis

\footnotetext{
${ }^{5} \mathrm{QE}$ is called Large Scale Asset Purchases (LSAT) in the US, Asset Purchases Program (APP) in the Eurozone, Quantitative and Qualitative Easing (QQE) in Japan. Related interventions are Long term Refinancing Operations (LTRO) in the Eurozone, but these are not QE proper, as they focus on improving intermediation. The increase in the size of the balance sheet is a, possibly unwanted, byproduct, that is demand, not supply-driven.
} 
banks have also bought privately issued assets either because they wanted to enhance monetary policy transmission by removing risk from bank balance sheets or because they wanted to reduce the borrowing costs of corporations. The counterpart of these purchases is base money creation.

The relevant monetary theory principle is the assertion that money and the price level grow hand in hand. QE, therefore, should lead to an acceleration of inflation. Figure 1 shows the case of the US. The upper chart indicates that the relationship was largely verified until QE was started, and then broke down. The lower chart focuses in more detail over the period 2003-2006. It shows that the link started to deteriorate before the crisis. The gradual deterioration of the relationship and its full-blown breakdown suggest serious limits to elementary principles.

Central banks can expand the monetary base at will when the interest rate is at the ZLB (Borio and Zabai, 2016), but monetary policy requires that monetary aggregates also increase, or that interest rates decline along the yield curve, or both, as discussed below. The link from the monetary base to the monetary aggregates is the well-known multiplier. If, as shown in Figure 2, the multiplier declines toward zero, a key link disappears.

The link to prices and output operates through increased spending. Under normal conditions, spending responds and the Phillips curve mechanism delivers the expected effect. Yet, there may be conditions when monetary aggregates fail to raise spending and when the effect of economic activity on inflation may be limited. The apparently feeble impact of economic activity on inflation is the object of current research. Ball and Mazumder (2011) find that the slope of the Phillips curve declines when inflation is low and stable. Blanchard (2016b) points to the role of strongly anchored expectations and to the general imprecision of the

Figure 2. M2 and the Fed's Balance Sheet, January $2003=100$

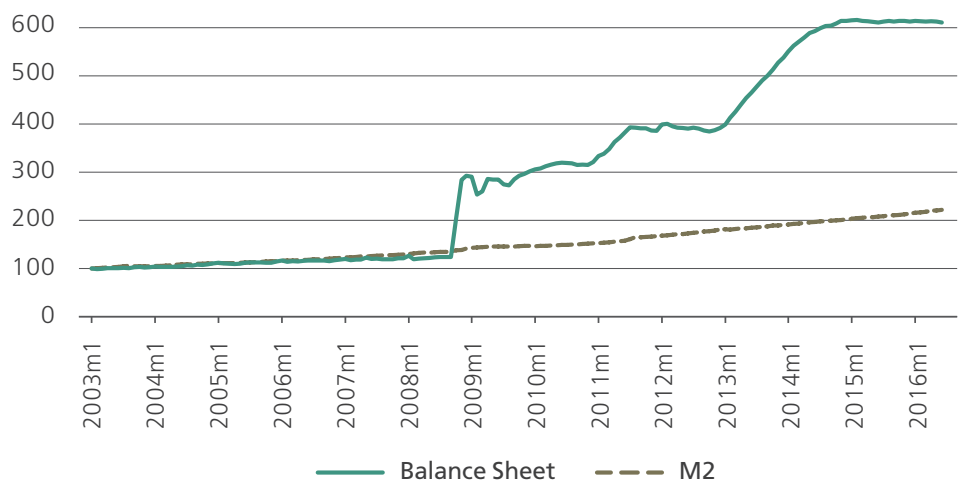

Source: FRED, Federal Reserve Bank of Saint Louis 
relationship. To understand why the economy may fail to respond to monetary aggregates, or responds with decreasing effectiveness, it is necessary to examine the various channels of unconventional monetary policy.

\subsection{The direct interest rate channel}

A lower interest rate is expected to increase spending by households and firms by encouraging borrowing as it affects the intertemporal price of consuming and saving. Additionally, the exchange rate is expected to depreciate, which should raise net exports.

\section{Low and negative interest rates}

Long-term rates matter more than short-term rates. As a consequence, the short-term policy rate can have an effect on economic activity only if lowers the whole yield curve. This, in turn, requires that market expectations concerning the future evolution of the policy rate, both its level and the duration of the current policy stance, respond to monetary policy decisions. When the policy rate is perceived to be close to the ELB, the only direction of substantial future changes in the policy rate is upward. This situation prevents a further lowering of the longer end of the yield curve. This is why central banks have developed the signaling channel as they wish to indicate that the policy rate will remain low or negative for a long period. This has worked well, as indicated e.g. by Bean et al. (2015). Yet, the presence of a lower bound suggests that there is increasingly less room for the level effect, leaving only the duration effect.

However, the adverse effects of low or negative interest rates could hamper the duration effect. These adverse effects include aggressive risk-taking by investors and financial institutions eager to achieve better returns, more difficult price discovery (Santor and Suchanek, 2016), the risk of disintermediation, and reduced bank profitability (Brunnermeier, 2016). If these adverse effects do not last for too long, they are likely to be harmless. However, persistent risk-taking, mispricing and reduced profitability are bound to become toxic and, possibly, contractionary (Brunnermeier and Koby, 2016). At best, steps taken by financial institutions to mitigate growing vulnerabilities will reduce monetary policy effectiveness, possibly reversing the impact when markets increasingly expect that the policy rate will be raised and the yield curve will steepen. At worst, market fragility may lead to a crisis.

Even if the yield curve can be kept flat, possibly in negative territory along the $E L B$, the question is what happens to the economy. An important issue is why the previous interest rate reductions - those that brought the policy rate to the ELB - 
have failed to lift spending. A variety of reasons have been invoked. Potential borrowers may be over-indebted and potential lenders may be over-leveraged. Lower rates shift income from lenders to borrowers, which may help with overindebtedness but at the expense of over-leveraging. Under these conditions, it is unclear why lowering the interest rates further would be more successful than previous reductions.

In addition, intertemporal substitution increases spending today at the expense of spending tomorrow. To sustain spending next year, a new lowering of the interest rate is needed. When the end of lowering interest rates is nearing, because the ELB is close by, further intertemporal substitution becomes impossible. Keeping the interest rate low does not provide continuing stimulus. Indeed, time must come when spending falls because it has been brought forward previously.

Another aspect is the pass-through of lower wholesale interest rates to rates applied to consumers and firms. Bean et al. (2015), among others, report that the pass-through is limited when the policy rate is close to zero. In some countries, banks cannot charge a negative interest rate. Where they may, they are reluctant to upset commercial relationships with customers. In addition, a flat yield curve erodes the profits from maturity transformation. If competition is imperfect, banks may elect to not lower their lending rates much.

\section{Quantitative easing}

Large asset purchases by the central bank raise asset prices and therefore lower their interest rates. The intention is to encourage borrowing or share issuance to prompt more spending by consumers and firms through lower borrowing costs and wealth effects. As stated, quantitative easing does not look different from standard open market operations. In that case, the impact from lower short-term policy rates to relevant longer-term rates is driven by market expectations of future policy rates, which can be strengthened through signaling. Other asset classes are affected by portfolio rebalancing, see next channel. However, quantitative easing differs from standard policy because central banks can choose which assets and amounts they purchase, thus acting directly on particular interest rates and asset classes.

By and large, the reasons why policy effectiveness might be decreasing are similar to those examined in the previous section. An additional consideration is that the volume of assets to be bought is finite. If the central bank holds a significant share of some assets, the relevant market becomes shallow and therefore less efficient. It follows that there is limit to what central banks can purchase, aptly called the Effective Quantitative Bound (EQB) by Santor and Suchanek (2016). As 
we move closer to the (unknown) EQB, markets may anticipate that $\mathrm{QE}$ is reaching its limits. Furthermore, the associated uncertainty can raise risk premia across the board.

Another often noted side effect is the emergence of asset price bubbles. Mechanically, QE raise asset prices. These prices can remain at their fundamental level as long as they are matched by the present value of future earnings evaluated at prevailing low interest rates. Yet, because QE is by definition temporary, asset prices are expected to fall back once liquidity is being removed. Thus the long-run resale value must be lower than current prices, with considerable uncertainty as to when exit will take place and at which pace. The result is that the wealth effect may become smaller as asset prices rise and that the expectation of a subsequent crash may build up as QE unfolds.

\subsection{The portfolio balance channel}

As any other price change, a lower policy rate is transmitted to other returns through a general equilibrium effect as investors rebalance demand for all asset classes. The portfolio balance channel captures investors' willingness to take on more risk when the policy rate declines and risk premia decline across the board.

\section{Low and negative interest rates}

Textbook models show that policy rate reductions lead to portfolio reallocation which ultimately result into higher asset prices. The question is whether this mechanism becomes less effective when the policy rate approaches zero or enters into negative territory. In other words, what can challenge the presumption that changing the policy rate triggers asset price changes and generalized portfolio reallocation when the rate is announced to remain low, or even negative, for long?

A first question concerns the pass-through from the policy rate to asset returns. While sovereign bond yields have responded to policy rate cuts and sometimes went into negative territory, corporate bond yields have not fully followed $^{6}$. Moreover, nominal illusion could limit the ability to issue bonds with negative rates below a certain threshold.

Finally, in principle, asset prices are the present discounted value of future earnings. These (mostly implicit) calculations are problematic when the discount rate is negative (or even close to zero), if only because the present value may

\footnotetext{
${ }^{6}$ For instance, over 2008-2016, the spread between Aaa 10 year US corporate bonds and 10 US Treasuries has ranged between 150 and 250 basis points, with an average of 185 basis points. The long run (1953-2016) average of this spread is 93 basis points and the 1953-2008 average is 76 basis points.
} 
become unbounded. This is one reason why markets fear "bubbles", in fact major uncertainty rather a "bubblish" equilibrium. A possible reaction is that the attendant uncertainty results in higher risk premia and therefore a muted response as the de facto discount rate does not decline as usual. Although, as indicated below, there is substantial evidence that the pass-through has remained active, these features suggest that its size may become increasingly smaller resulting in decreasing effectiveness.

\section{Quantitative easing}

As some assets are withdrawn and their prices increase, investors rebalance their portfolios by acquiring other assets. If the supply of these other assets does not increase to meet higher demand, their prices increase and their yields decline. This is indeed a key channel of transmission. Central banks rely upon this channel to spread the impact of QE through lower term and risk premia.

The possible downside is that risk becomes mispriced and that investors including banks, insurance companies and pension funds - ride up the flattened risk-return schedule with improper understanding of risk being taken or by accepting risk because of pressing search for yield. As QE unfolds, more risk may be taken. This may not result in immediate loss of effectiveness but into subsequent financial difficulties once QE stops and is reversed.

\subsection{The confidence channel}

Unconventional policies are meant to signal that the central bank stands ready to take exceptional action when other standard means are no longer available. In addition, the ability to target specific assets implies that the central bank can address specific financial concerns, as with TARP in the US. Both readiness to act and the emergence of new instruments could help dispel fears on financial markets and beyond that serious problems remain unaddressed (Curdia and Woodford, 2011). The confidence channel is expected to boost spending, both directly by improving expectations, and indirectly by reducing interest rate risk premia.

Since what matters is the signaling impact of the policy measures, we can consider negative rates and QE together. Both policies face the same challenge that the room for maneuver declines as the policies unfold. Negative rates are limited by the unknown ELB, QE is ultimately limited by the size of the markets. These Knightian limits are bound to gradually erode policy effectiveness. They could even make nonstandard policies ineffective if faced with the perception that the end of the road is in sight and that the central bank has reached its limits and can no longer implement confidence-building measures. 
One specific aspect of $\mathrm{QE}$ is that asset purchases can be used to repair malfunctioning markets where demand is reduced by fears of impending crisis. When confidence has returned in the affected markets, QE stand to be less efficient. This was the case in 2007-2009. Indeed several papers (Krishnamurthy and Vissing-Jorgensen, 2013; Fratzscher et al., 2014) detect such an effect early on, but none once markets were stabilized.

\subsection{The bank credit channel}

The literature on the credit channel (or financial accelerator, Bernanke and Gertler, 1995) argues that ample availability of liquidity encourages banks to increase lending, over and above its impact on the interest rate, meaning that this channel is specific to QE. When banks hold large amount of cash, they have a choice of holding it as part of their reserves at the central bank, or to lend it to customers. Under the assumption that bank-lending rates exceed central bank deposit rates, it is expected that banks will prefer to lend to customers. Easier credit terms, in turn, are expected to encourage spending by both households and firms.

The bank credit effect could be muted when banks and/or their customers are highly leveraged. Thus, in contrast to the confidence channel, QE might become more effective when the situation improves.

Decreasing effectiveness may arise if nonstandard policies lead banks to chasing increasingly less reliable borrowers. In that case, either lending rates will rise or lending will start decreasing. Indirect evidence is provided by Figure 2, which plots the size of the balance sheet of the Federal Reserve - already shown in Figure 1 - and the monetary aggregate M2. The ratio between these two measures is the money multiplier, which captures the banking system lending response to liquidity injections by the central bank. As is well known, the money multiplier has declined considerably since the start of QE: the ratio of M2 to the size of the Fed's balance sheet has declined from an average of 8.1 over 2003-2007 to 3.7 over 2009-2012 and 2.8 since 2013.

\subsection{The sovereign credit risk channel}

The interest rate paid by the Sovereign usually serves as the basis for all interest rates in the country. This is because sovereign debt is, rightly or wrongly, treated as a safe(r) asset. It follows that any policy action that lowers ceteris paribus the interest rate on the sovereign debt is potentially equivalent to a direct reduction of the policy rate. Government debt purchases by the central bank in effect reduce public sector indebtedness because debt service on purchased instruments implies 
payments to the central bank, which rebates profits to the Treasury. Equivalently, the public sector swaps interest-bearing debt for zero interest-bearing money. Insofar as a lower debt reduces the sovereign risk premium, this is an additional channel.

The channel faces limits, though. The temporary nature of QE means that the corresponding amounts of public debt are not fully written down; debt service is reduced only as long as $\mathrm{QE}$ is in place. The resulting reduction in risk premia is bound to be reversed as the end of QE becomes nearer. The "taper tantrum" of 2013 could be a manifestation of this effect (Foerster, 2014).

\subsection{The international portfolio balance and exchange rate channels}

Finally, the portfolio rebalancing process means that residents will acquire foreign assets, possibly in amounts commensurate with the central bank purchases. This should lead to a depreciation of the exchange rate. In small open economies, the exchange rate channel is usually the main channel of standard monetary policy.

\section{Low and negative interest rates}

In principle, the effect of the policy interest rate on the exchange rate is independent on its size.

\section{Quantitative easing}

The experience so far is that the large countries have adopted QE policies more or less at the same time. As a result, their effective exchange rates have not moved much (Caballero et al., 2016; Eggertson et al., 2016). More significant movements have affected a host of other countries, but this is not an issue related to this paper.

\section{Overview of the Evidence}

A growing number of studies are attempting to evaluate the effectiveness of unconventional monetary policies. With a very short sample period, much of the early work has relied on high frequency observations and focused on the effect of nonstandard policies on various asset prices or on measures of asset price volatility.

The impact of macroeconomic variables, which move much more slowly, has been examined only recently ${ }^{7}$.

\footnotetext{
${ }^{7}$ A number of studies are summarized in Den Haan (2016) and Borio and Zabai (2016).
} 
Given the unsettled economic and financial situation, a key challenge is to disentangle the influence of policy decisions from other contemporaneous shocks, including those that affect financial markets and lead central banks to enact nonstandard policies. As noted by Borio and Zabai (2016), two methods have been used ${ }^{8}$.

First, using various types of VAR analysis, some authors test whether nonstandard policies affect the variables of interests. To be valid, these tests should not include observations that predate the adoption of non-standard policies since these policies are designed to significantly alter the operations of financial markets. Identification is particularly challenging because policy announcements are likely to be more important for asset markets than actual implementation. For instance, daily or monthly asset purchases may have little impact once the schedule of purchases has been announced. This is why more recent papers have focused on policy announcements and event studies.

\subsection{Effects of QE on Financial Markets}

Empirical evidence from the US, the UK and the Eurozone strongly backs the existence of an effect of QE on asset prices and interest rates at all maturity. In the case of the US, Krishnamurthy and Vissing-Jorgensen (2013) provide early evidence that the portfolio balance channel has been effective. This evidence has been confirmed by a large number of studies, incuding Engen et al. (2015), Gagnon et al. (2011) and Wu and Xia (2015). Qualitatively similar results are reported for the UK by Kapetanios et al. (2012) and the Eurozone by Frazscher el al. (2014).

Other channels have also been identified. Bauer and Rudebsuch (2014) separate out the portfolio balance channel from the interest rate channel in the US and conclude that both have been operative. Altavilla and Giannone (2015) reports evidence on the interest channel via private forecasters in the US and the Eurozone. There is also some evidence that the risk channel operates in the US and the Eurozone (Carpenter et al., 2013).

The bank liquidity channel is supported by studies that focus on the early phase of the financial crisis (e.g., Krishnamurthy and Vissing-Jorgensen, 2013, for the US, Darracq-Paries and de Santis, 2013, in the case of the Eurozone). Hong (2016) documents the lengthening of the maturity of bank loans in the US.

\subsection{Effects of QE on Output and Inflation}

Fewer studies so far looked at the ultimate criterion of success of non-standard policies, namely whether they boost output and inflation. An important roadblock

\footnotetext{
${ }^{8}$ Borio and Zabai (2016) also mention simulation with DSGE models extended to include various financial frictions. This is not empirical evidence, however, as they rightly observe. These studies are properly understood as illustrating under which assumptions non-standard policies can produce some specific effects.
} 
has been the measurement of unconventional policies. Macroeconomic variables cannot be measured at high frequency so that the small sample period available implies that too few observations are available. The solution is to extend the sample back to periods when unconventional policies were not in use. In principle, one can measure both the policy rate and the size of central bank balance sheets over long periods but it is likely that the adoption of unconventional policies represents a regime change.

A breakthrough has been the estimation of a shadow policy rate by $\mathrm{Wu}$ and Xia (2015). They use the term structure to model the shadow policy rate as a function of standard factors and allow this rate to diverge from the near-zero actual policy rate. Of course, the estimated shadow rate is subject to a number of assumptions. Using this shadow rate, Ball et al. (2016) shows that QE in the US has reduced shadow policy interest rates by 200 to 300 basis points and conclude that there must have some output and inflation effect. Churm et al. (2015) perform a similar exercise for the UK.

More direct evidence is provided by a few studies that include output and/or inflation in various VAR formulations. Baumeister and Benati (2010) use the longterm interest spread at unchanged policy rate as a measure of QE in a time-varying SVAR that also include GDP growth and the GDP deflator inflation. They report a significant macroeconomic impact in the US, UK and the euro area. Weale and Wieladek (2015), which is the paper closer to ours, use Bayesian VAR (BVAR) model that includes monthly data for GDP, CPI, asset prices and long-term rates and show that asset purchase announcements have a statistically significant effect on prices and GDP in both the US and the UK. Garcia Pascual and Wieladek (2016) apply a similar methodology to the Eurozone and also find a significant effect of quantitative easing on prices and output. Haldane et al. (2016) evaluate the early evidence on quantitative easing (besides the UK, US and Eurozone, they also study the cases of Canada, Japan, and Sweden) corroborate the finding that quantitative easing has significant effects on prices and output. They also show that the $\mathrm{QE}$ is more effective in the presence of financial frictions ${ }^{9}$.

\subsection{Negative Interest Rates}

The experience with negative interest rates is even more recent than with QE, making it challenging to seek formal evidence. The focus so far has been on the transmission of negative rates on financial conditions. Bech and Malkhozov (2016) informally find that negative policy rates have been transmitted to most other interest rates, with some exceptions like mortgage rates. Coeuré (2016) describes

\footnotetext{
${ }^{9}$ Along similar lines, Vitale (2016) shows that monetary policy is more powerful when firms face financial distress.
} 
the ECB policy and accepts that adverse effects may set in because banks may eventually have to change their business models and, mostly, because there is still a minimum interest rate.

\subsection{Non-Linearities and the Decreasing Effectiveness Hypothesis}

A number of papers have started to explore the decreasing effectiveness hypothesis, following the initial hint by Goodhart and Ashworth (2013) and the early observation by Krishnamurty and Vissing-Jorgensen (2012). Barnichon et al. (2016) examine whether the financial accelerator mechanism may lead to nonlinearities. They find that increased credit supply has a stronger output effect in periods of weak growth when credit is constrained than during period of fast growth. They use data for the US on a long sample that includes the post-2008 period. Their results can be seen as implying that QE may have been more effective early on when financial markets were impaired and illiquid than when abundant liquidity had already been created (this finding is consistent with the results of Haldane et al., 2016, mentioned above). Similar results are reported for Japan's experience in the 2000s by Ueda (2012). For the QQE experiment started in 2013, Nishimura (2016) develops the view that "policy exhaustion" has set in, mostly in Japan but also in the US.

Kapetenios et al. (2012) conduct a counterfactual analysis of the Bank of England policies. They use three different VAR models (Bayesian over different windows, Markov switching, and time-varying parameters) estimated over long periods. They compare the impulse responses of GDP and inflation when longterm yields are reduced by 100 basis points. While these authors use time-varying estimates up to September 2010, they do not focusing on detecting changes within the QE period.

To the best of our knowledge, this paper is the first attempt to detect changes within the QE period ${ }^{10}$.

\section{Empirical Results for the US, UK, Eurozone and Japan}

There are two challenges associated with testing the hypothesis that unconventional monetary policies have decreasing effectiveness on economic activity. First, the short time span of these policies prevents us from using quarterly data, as it is commonly done in the monetary policy literature. Second, there is no commonly agreed quantitative indicator of unconventional monetary policies.

\footnotetext{
${ }^{10}$ The contribution by Demertzis and Wolff (2016) is closest to our own investigation in its intentions. Informally, it interprets the evidence as indicating that the ECB's QE had a positive effect on investment spending after its announcement in 2015 but that the increased decided in early 2016 did not produce such an effect.
} 
We address these challenges by using monthly data and two different proxies for non-standard monetary policies. Even with monthly data, we have limited degrees of freedom (especially when we try to assess whether the parameters vary over time). The point estimates may thus be sensitive to small changes in the sample or estimation technique. We address this issue by comparing the results of two different econometric approaches.

\subsection{Measuring unconventional monetary policy}

The policy stance of the central bank is normally measured with a policy interest rate (like the Fed Fund rate in the US) or with a monetary aggregate (such as M1 or M2, as originally suggested by Friedman and Schwartz, 1963). The presumption is that these instruments can be controlled by the central bank and are stably related to economic activity (Leeper et al., 1996). Unconventional monetary policy starts when the central bank loses control over these instruments, either because the policy rate approaches the effective lower bound (Figure 3a, b) or because the main monetary aggregates no longer respond to the injection of base money (Figure 2). This is why the evaluation of unconventional monetary policies requires alternative indicators of policy stance.

Our first indicator of unconventional policy is the "shadow" (i.e., nonobservable) policy rate derived from the yield curve. The shadow interest rate is an attempt at measuring how the policy rate would look like if the central bank had been willing (and able) to adopt a negative policy rate. One way to recover this shadow rate is to build a statistical model of the lower end of the yield curve and then use the model to build a counterfactual estimate for the overnight rate ${ }^{11}$.

The idea of using the yield curve to build a shadow term structure is due to Black (1995) and was recently operationalized for the US, UK, and the Eurozone by $\mathrm{Xia}$ and $\mathrm{Wu}(2016)^{12}$. Xia and $\mathrm{Wu}$ (2016) show that when the US policy rate is above 50 basis points, their estimate for the US shadow rate coincides with the observed rate (Figure 3a). The coincidence, instead, is not perfect for the UK and the Eurozone. In the case of Japan, instead, our shadow rate data start in 1995 and coincide with the period in which the Bank of Japan started adopting a policy of very low interest rates (0.5\% between 1995 and 2001 and $0.1 \%$ between 2001 and 2006$)^{13}$.

Xia and Wu (2016) also show that the shadow rate can be used to assess the effectiveness of monetary policy when the observed rate approaches zero. One advantage of using the shadow rate as a measure of policy stance is that this

\footnotetext{
${ }^{11}$ An alternative approach is to use a large number of variables and then estimate the shadow rate by applying dynamic factor analysis to these variables (Lombardi and Zhu, 2014).

12 Other papers that use the term structure to estimate a shadow policy rate include Christensen and Rudebusch (2015) and Krippner (2013).

${ }^{13}$ We source shadow rate for the Eurozone, UK and US from Xia and Wu (2016) and Japanese shadow rates from IMF (2015, Box 3.1).
} 
Figure 3a. Actual and Shadow Policy Rate
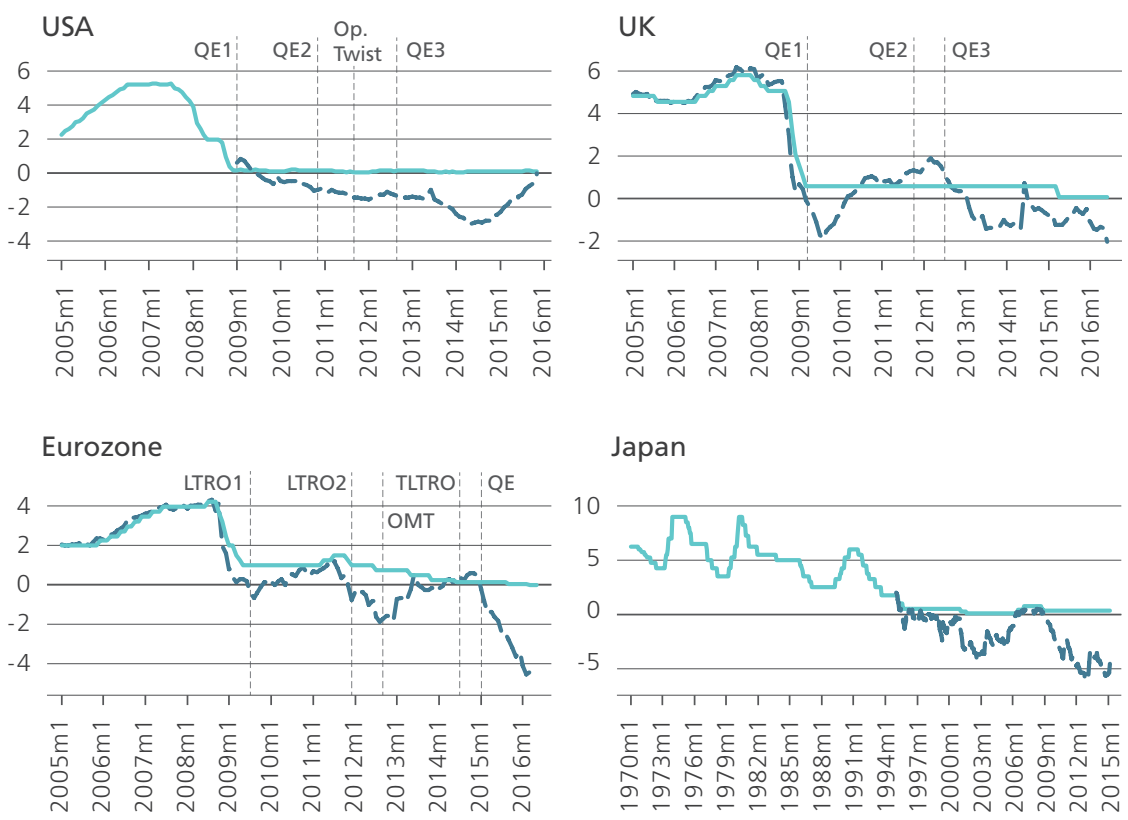

Japan

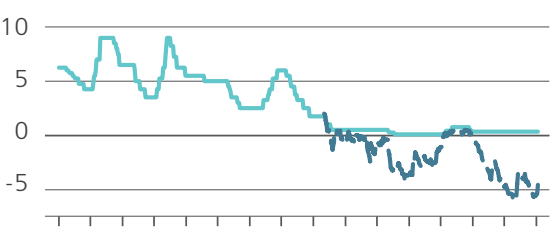

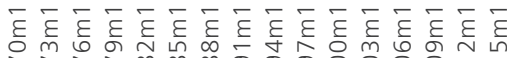

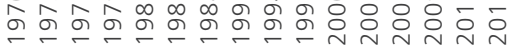

Shadow policy rate

Figure 3b. Shadow Policy Rate and Adjusted Shadow Policy Rate
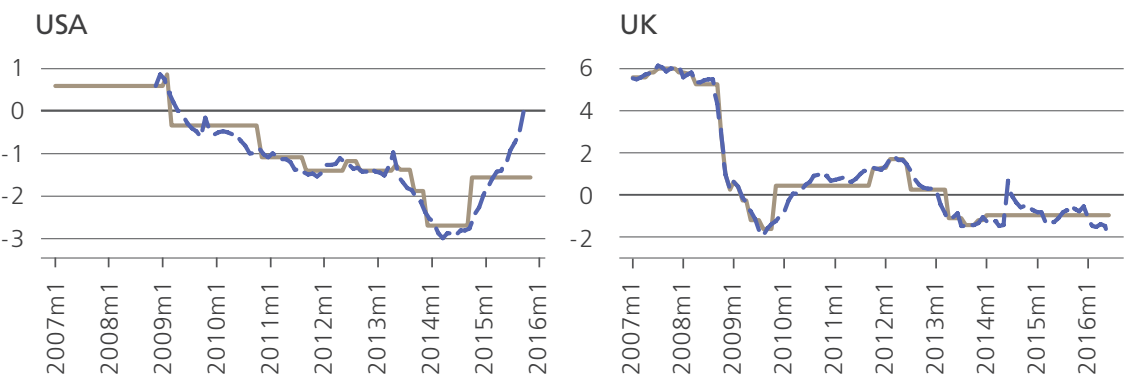

Eurozone

Japan
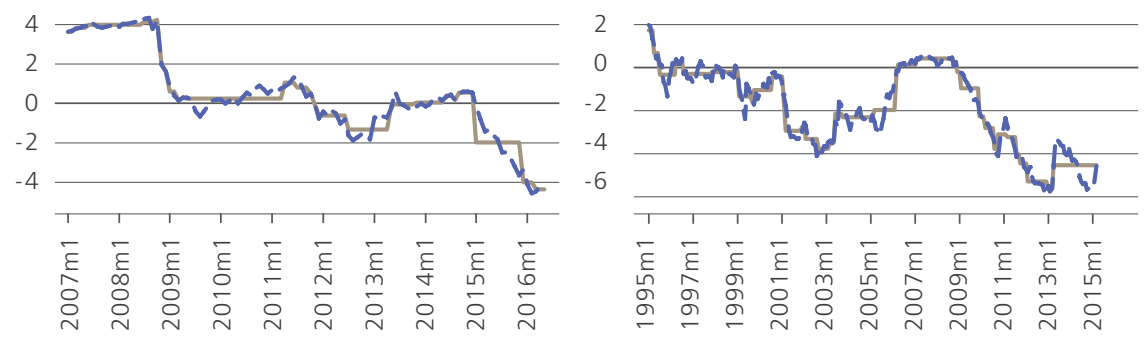

_ Adjusted shadow rate $\quad$ - - Shadow policy rate 
indicator is directly comparable with policy rates in normal times. One challenge related to the use of this measure is that the shadow rate is model-specific and that different specifications can yield alternative measures of the shadow term structure (Christensen and Rudebusch, 2015).

Another potential problem with the shadow rate is that any event that affects the slope of the yield curve will also have an impact on the estimated shadow rate, even if this event has nothing to do with monetary policy actions. While the unobservable shadow rate is not a policy instrument (it is a proxy for a series of unconventional monetary policy instruments, including the announcement of asset purchases), it can be treated as a policy instrument if we assume that policymakers target the shadow rate and reverse-engineer non-standard monetary policies to achieve this target ${ }^{14}$. Changes in the shadow rate could therefore be decomposed into changes linked to policy decisions and changes that are not directly related to policy decisions and are instead due to other factors that shift the slope of yield curve. To separate these two components, we compile a monthly dataset of monetary policy announcements (they could be changes in the policy rate, announcements of asset purchases, forward guidance, announcements about changes in monetary policy strategy) and build a proxy for the policy component of the shadow rate by regressing the shadow rate on a set of dummy variables that take a value of one during months for which there was a monetary policy announcement.

Formally, suppose that in a given country we identify $N$ policy announcements, then we estimate the following model:

$$
S R_{t}=\alpha+\sum_{i=1}^{N} \beta_{i} D_{i, t}+\varepsilon_{t}
$$

where, $S R_{t}$ is the shadow rate in month $t$ and $D_{i, t}$ is a set of dummies associated with policy announcements (we include as many dummies as policy announcements) $)^{15}$.

Finally we use the predicted values of this model to build an adjusted shadow rate that only varies in months characterized by a policy announcement. The adjusted shadow rate plotted in Figure $3 \mathrm{~b}$ is defined as:

$$
A S R_{t}=\hat{\alpha}+\sum_{i=1}^{N} \widehat{\beta}_{l} D_{i, t}
$$

We conduct all of our tests using the adjusted policy rate described in Equation (2). The results, however, are robust to using the unadjusted policy rate.

\footnotetext{
${ }^{14}$ We would like to thank an anonymous referee for pointing this out.

${ }^{15}$ Assume that there are 3 monetary policy announcement, the first in month $t$, the second in month $t+s$, and the third in month $t+s+z$. $D_{1}$ will take value 0 from month 1 until month $t-1$, it will then take value 1 from month $t$ to month $t+s-1$, and value zero from month $t+s$ to month $T$. $D_{2}$ will take value 0 from month 1 until month $t+s$-1, it will then take value 1 from month $t+s$ to month $t+s+Z-1$, and value zero from month $t+s+Z$ to month T. $D_{3}$ will take value 0 from month 1 until month $t+s+Z-1$ and value 1 from month $t+s+Z$ to month $T$.
} 
For our second indicator of unconventional policy, we use the announcements of large scale asset purchases (quantitative easing) by the Federal Reserve and the Bank of England. While this indicator has the advantage of being based on an observable measure of unconventional policy (unlike the shadow policy rate, it is not model specific), it has the disadvantages of not being directly comparable with standard monetary policy instruments and of not incorporating policy measures (such as forward guidance or the "whatever it takes" speech of July 2012) that go beyond and above asset purchases.

As the experience of the European Central Bank with quantitative easing is too short for our own purposes of evaluating potential decreasing effectiveness to this policy (see, however, Garcia Pascual and Wieladek, 2016, for an evaluation the macroeconomic effects of quantitative easing in the Eurozone), we experiment with the size of balance sheet of the European Central Bank. We do the same for Japan, but for the opposite reason. Since 1999, the Bank of Japan has sporadically expanded its balance sheet but changing clarity in its communication severely hampers the use of QE announcements by the Bank of Japan.

Figure 4 shows the evolution of the balance sheets of the US Federal Reserve, Bank of England, and European Central Bank. The figure also plots the data for asset purchase announcements.

Figure 4. QE Announcements and Central Bank Balance Sheets
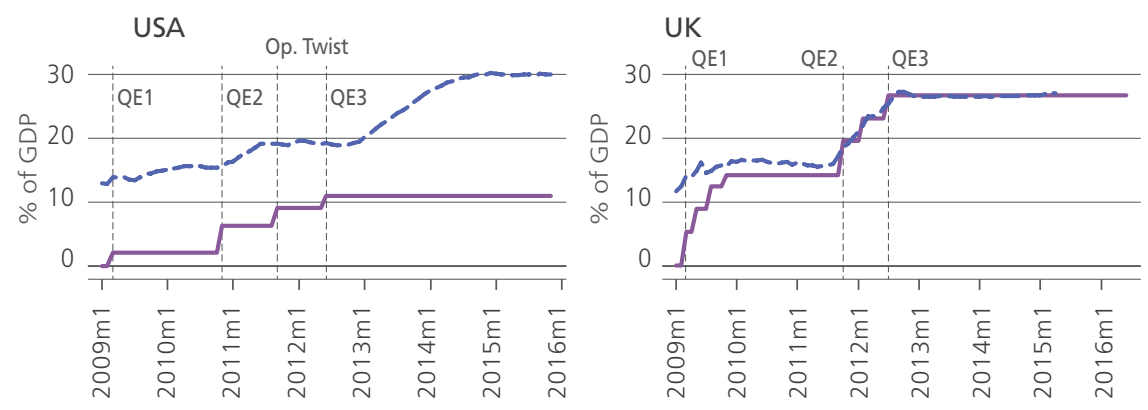

Eurozone
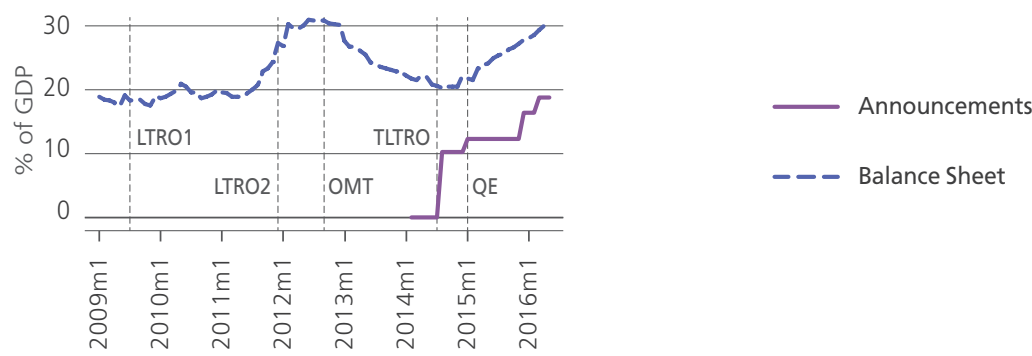


\subsection{Econometric Strategy}

We follow Weale and Wieladek (2015) and identify the output and price effects on non-standard policy with a Bayesian VAR with sign restrictions. In the Appendix, we summarize results obtained with an alternative approach, local projections.

There are tradeoffs related to the use of these estimation techniques. Local projection requires identifying the policy instrument to solve the standard endogeneity problem. The Bayesian VAR has the advantage of allowing modeling the complex interactions among all variables but it absorbs a larger number of degrees in freedom, which is problematic as the sample size of QE periods is limited. Multicollinearity among the variables included in the VAR can amplify the problems associated with limited degrees of freedom ${ }^{16}$. These problems could be attenuated by imposing tight priors in the BVAR estimates. However, tight priors also have costs because they may not let the data speak.

Specifically, we use monthly data to estimate the following reduced-form VAR model:

$$
Y_{t}=A+B_{1} Y_{t-1}+B_{2} Y_{t-2}+E_{t}
$$

Where $\mathrm{Y}$ is a vector of the following six variables: (i) the log of monthly GDP; (ii) the log of the consumer price index (CPI); (iii) the log of real equity prices (measured by dividing a stock market index by the CPI) (iv) the yield on ten-year government bonds, $(v)$ the log of the effective exchange rate and ( $v i)$ a measure of unconventional monetary policy. With respect to this last variable, as mentioned above, we use alternatively the adjusted shadow policy rate and announcements of asset purchases. $B_{1}$ and $B_{2}$ are matrixes of parameters associated with the lagged dependent variables and $E$ is a vector of normally distributed residuals with mean zero and variance covariance matrix $\Sigma$.

In order to interpret the results of the reduced form VAR, it is necessary to impose a set of identifying assumptions that allow recovering the structural parameters from the estimates of $B_{1}, B_{2}$ and $\Sigma$. We adopt the same sign restrictions as in Weale and Wieladek (2015) in assuming that expansionary policy at the zero lower bound signals that expansionary unconventional policy reduces long-term interest rates and increases real equity prices at impact and also for the month that follows the policy action. We also follow their strategy of identifying demand and supply shocks: with a positive demand shocks both output and prices increase, and this also leads to an increase in the long-term interest rate and real equity prices;

\footnotetext{
16 These problems are compounded by the fact that monthly GDP data are noisier than the quarterly data which are normally used to estimate the effect of monetary policy.
} 
with a positive supply shock, income increases, prices decrease, and long-term interest rates and real equity prices increase ${ }^{17}$.

When we estimate the Bayesian VAR with announcements of asset purchases, our model is almost identical to that of Weale and Wieladek (2015). There are, however, three notable differences. First, we assess the decreasing returns hypothesis by estimating the model over different subsamples. Second, we augment their model with the log of the effective exchange rate (their model only includes 5 variable). While including an additional variable has a cost in terms of degrees of freedom, we feel that it is important to control for the exchange rate which has been found to be an important channel of effect of conventional and unconventional monetary policies (see, e.g. Caballero et al. 2015) ${ }^{18}$. Third, we study more countries (or group of countries, in the case of the Eurozone) and have a slightly longer sample (approximately one extra year of data).

When we estimate how the adjusted shadow rate affects prices and GDP, we add one restriction to those listed above. Specifically, we restrict the contemporary impact on prices and output of a reduction of the adjusted shadow rate to be nonnegative ${ }^{19}$. While this additional restriction rules out that an expansionary monetary policy (as captured by the adjusted shadow rate) will lead to lower output or prices on impact, it does not rule out the possibility that expansionary policy will have a negative effect on output and prices starting one month after the implementation of the policy. As we maintain this restriction for all subperiods for which we estimate the model, the restriction does not affect the relative magnitude of the output and price responses across estimation periods (which is what we are interested in).

We use the same uninformative priors as Weale and Wieladek (2015) who, in turn, follow Uhlig (2005) in assuming that the priors are drawn from a NormalWishart density multiplied with an indicator variable that takes a value one when the impulse response satisfies the sign restriction. Therefore, the priors and identification strategy are not exogenously chosen for each country. They are instead based on the country-specific impulse response functions that satisfy the sign restrictions.

\section{Testing for the decreasing effectiveness hypothesis}

Going back to the discussion of Section 2, we use different subsample to look at how $\partial f / \partial x$ varies when $x$ surpasses a certain threshold or to check if the value of $\partial f / \partial x$

\footnotetext{
${ }^{17}$ Weale and Wieladek (2015) experiment with 4 alternative identifications schemes. The first is a simple Cholesky ordering, the second imposes a series of sign restrictions, the third jointly uses sign and zero restrictions, and the fourth uses sign and variance decomposition restrictions. In our baseline model we use the second identification scheme, but we also experiment with the third identification scheme.

${ }^{18}$ As we are only interested in estimating the impact of nonstandard policy on the other 5 variables, the inclusion of the exchange rate does not require additional identification restrictions.

${ }^{19}$ If we do not impose this restriction, we obtain imprecise estimates (i.e., much larger confidence bands) across subperiods.
} 
is affected by the duration of the nonstandard policy. There are at least two possible ways to test for the decreasing effectiveness hypothesis. One possibility is to explicitly allow for non-linearities by, for instance, including the square of the adjusted shadow rate or squared asset purchases ${ }^{20}$. Another possibility is to check whether the effectiveness of unconventional monetary policy has decreased over time by splitting the sample into different sub-periods. We opt for the second option because it is difficult to explicitly include non-linearities in the VAR framework described above. Moreover, it would be problematic to work with the square of the shadow policy rate as the shadow rate can take on negative value and a quadratic model would imply that a shadow rate of, say, $2 \%$ is as effective as a shadow rate of minus $2 \%$.

When we work with asset purchases announcements in the US and the UK, we first estimate the model using data for the full QE period (2009M1-2015M11 for the US and 2009M1-2016M5 for the UK) and then use thresholds that are based on the size of asset purchases. We choose sub-periods of similar length but that also coincide with different phases of unconventional monetary policy. For instance, for the US the first period covers QE1 and QE2 and the second period encompasses Operation Twist and QE3. In the case of the UK, instead, the first period covers QE1 and the second period QE2 and QE3.

In the case of Japan, instead, we use data on central bank balance sheet (always scaled by GDP) for the first (2001M1-2008M7) and second (2008M8-2016M5) QE experiments and then we further split the second period into sub-periods of similar length (2008-2013 and 2012-2016). We also experimented with the balance sheet of the European Central Bank and different sample splits. However, either the program did not converge or produced unstable results.

When we work with the policy rate and the adjusted shadow policy rate, we start by estimating the model with the actual policy rate in the pre-nonstandard policy period (1995-2008 for the US and the UK, 1999-2008 for the Eurozone, and 1978-2000 for Japan). Next we estimate the model for the post Global Financial Crisis period (2008-2016) for the US, UK, and Eurozone, and for the full QE period for Japan (2001-2016). Finally, for the US, UK, and Eurozone we split the nonstandard policy subsample in two sub-periods of similar length (2008-2012 and 2011-2016) and for Japan we split the sample between the first and second phase of nonstandard policy (2001-2005 and 2005-2016) ${ }^{21}$.

Note that when we estimate the models for the US, UK, and Eurozone we include data up to 2012M6 in the first sub-period and start the second sub-period in 2011M6. This small overlap between the two subsamples allows us to have at

\footnotetext{
${ }^{20}$ For the adjusted shadow rate one could define the following variable: $S A S R=N_{X} A S R^{2}$, where $A S R$ is the adjusted shadow rate and $N=-1$ when $A S R<0$ (with $N=0$ when the adjusted shadow rate is nonnegative)

${ }^{21}$ We also estimated models where we split the 2005-2016 period in two subsamples of similar length but did not find any interesting result.
} 
least 50 observations for each period but can potentially bias our estimates against finding different responses to monetary policy in the two periods.

In describing the results of the various exercises described above, we will compare the magnitude of the responses of output and prices to monetary policy across sub-periods and also discuss whether the responses are statistically significant in one period and not in another one. Our confidence bands often overlap across periods and formal tests show that the difference of the impulse response functions across sub-periods is rarely statistically significant. This lack of a statistical significance could be due to one of two factors: (1) there is no difference between the two periods; or (2) our short estimation period and the fact that in some cases there is an overlap between the two samples do not give us enough power to precisely estimate the difference across periods. The fact that the difference between impulse responses is not generally statistically significant across subperiods is an important caveat to our conclusion.

\section{Data}

As mentioned above, all of our estimations use monthly data with different starting points and up to 2015M11 for the US, 2016M5 for the UK, Eurozone and Japan. GDP data for the US are from Macroeconomic Advisers, GDP data for the UK are from the National Institute of Economic and Social Research, and we use industrial production for the Eurozone and Japan (from the Eurostat and the Bank of Japan, respectively).

Price index (CPI) and policy rate data for the US and the UK are from the FRED database maintained by Saint Louis Fed. For the Eurozone, instead, we use data from the European Central Bank (we measure the policy rate with the ECB refinancing rate) and for Japan we use Bank of Japan data.

The shadow policy rates are for the US, UK, and Eurozone are from Xia and $\mathrm{Wu}$ (2016) and for Japan are from IMF (2015), data on announcements of asset purchases for the US and UK are from Weale and Wieladek (2015) and data on the balance sheet of the ECB and Bank of Japan are from the respective central banks.

Finally, data on equity prices and long term interest rates are from Datastream. For the Eurozone, we measure long-term interest rate using 10-year German bunds and equity prices using a weighted average of the French, German, Italian, and Spanish stock markets ${ }^{22}$.

\footnotetext{
${ }^{22}$ We use the following weights: German DAX 0.3, French CAC 0.3, Italian MIB 0.2, and Spanish IBEX 0.2. These weights reflect the different capitalizations of these 4 stock markets before the global financial crisis. For the UK and the US, we use the FTSE 100 and S\&P 500 indexes, respectively. We use the German bunds because our intention is to control for how unconventional policy actions are reflected in the long-term risk-free rate. It may be, however, claimed that the objective of non-standard policy in the Eurozone was to reduce the risk premium in the periphery. Our results are robust to substituting the German Bund rate with the average yield of German Bunds and Italian 10 year government bonds.
} 


\subsection{The effect of unconventional policies as proxied by the adjusted shadow policy rate}

We look at the impulse response functions of the log of GDP and of the log of the price level to a 1 percentage point decrease in the shadow policy rate at time $\mathrm{t}=1$. The figures that follow display the mean response (continuous line) along with the $68 \%$ Bayesian confidence intervals (dotted lines) drawn from 500 MonteCarlo simulations.

\section{Preliminaries: the interest and exchange rates}

In order to understand the results, we first need to understand how the data capture the behavior of the adjusted shadow policy rate. Figure 5 shows its own response to a one-off shock to itself. For each country, the two upper charts correspond to the pre-and post-financial crisis periods, respectively. The results differ across countries. In the US and the UK, conventional cuts in the actual policy interest rate are long lasting: a policy change is sustained over the horizon period of 24 months and the confidence interval is narrow. Unconventional policies are both more variable and less precisely estimated. The adjusted shadow policy rate first continues to be reduced before rising after about one year in the US and 6 months in the UK where it becomes higher than initially, although not significantly so. The pattern is the opposite in the Eurozone, with an immediate reversal in the period before the crisis and a stable pattern after 2008. In Japan, the policy is reversed over both sub-sample periods.

The two lower charts focus on the post-crisis period. Except for Japan, this period is divided in two equally sized subsamples. In all countries, the adjusted shadow policy rate reduction is reversed in the first sub-period, and this is also the case for the second sub-period on Japan and the UK. The reduction is maintained in the US and the Eurozone. Keeping in mind that the adjusted shadow policy rate (as estimated from the yield curve and signaled by policy announcements) includes actual interest rate cuts and the battery of unconventional policies once the actual rate approaches zero, the presence of reversals can be interpreted as a sign of lack of credibility. Under that interpretation, the unconventional policies of the US and the Eurozone during the last sub-period can be seen as more credible than in Japan and the UK. This pattern may have an impact on the output and price effects through asset prices and the confidence effect.

Such an interpretation is partly confirmed by the evolution of the effective exchange rate displayed in Figure 6. A cut in the shadow policy rate is expected to lead to a depreciation, which is partly confirmed. In all countries and periods, the initial depreciation is progressively reversed, however. This is particularly the 
Figure 5. Shadow policy rate response to the shadow policy rate

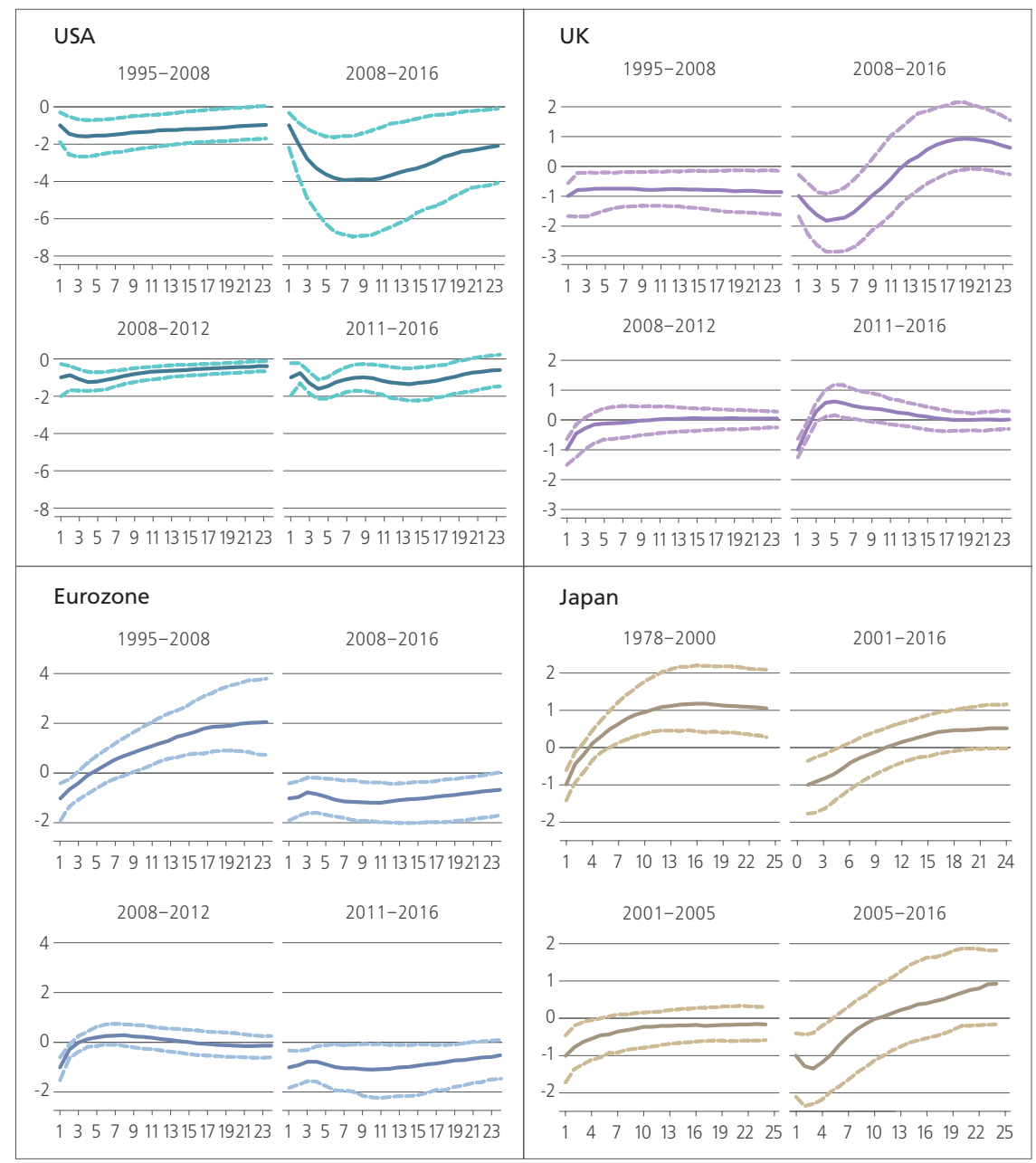

The solid lines plot the median responses of the shadow policy rate to a 1 percentage point decrease of the shadow policy rate. The dashed lines plot the 68\% Bayesian credible confidence set. The impulse response functions are computed using a Bayesian VAR with the sign restrictions described in the text and the following variables: log of GDP (industrial production for Japan and the eurozone), log CPI, long term interest rate (10 year bond rate), adjusted shadow policy rate, real equity prices, log effective exchange rate.

case in the post-crisis period. A possible explanation is that many countries adopted similar policies and thus neutralized potential beggar-thy-neighbor effects. This interpretation is supported by the observation that the initial depreciation was stronger in the US and the UK, which moved earlier than the Eurozone and Japan. 
Figure 6. Exchange rate response to the shadow policy rate

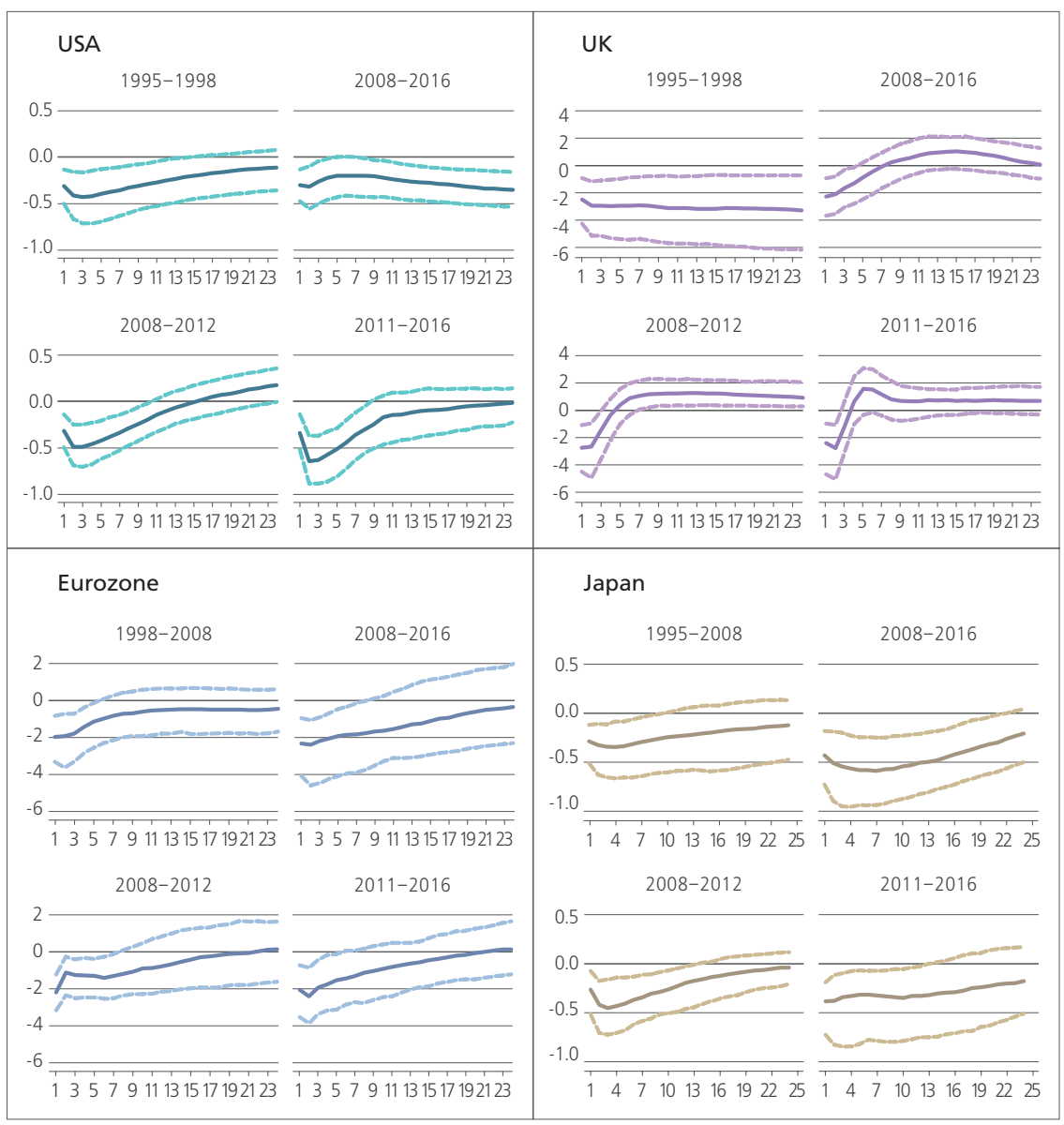

The solid lines plot the median responses of log effective exchange rate (an increase of the index is an appreciation) to a 1 percentage point decrease of the shadow policy rate. The dashed lines plot the $68 \%$ Bayesian credible confidence set.

\section{Output and price effects}

Figures 7 reports the response of $\log$ GDP to an adjusted shadow policy rate shock - as before, a 1 percentage point cut - and Figure 8 reports the response of $\log$ CPI. They are structured as the previous figures.

Except for Japan, the output effects are smaller during the post-crisis period (upper panels) and this is mostly due to decreasing effectiveness in the most recent period (lower panels). The same observation applies to price effects, although they seem to be stronger after 2011 in the UK. For these countries, therefore, these results are consistent with the decreasing effectiveness hypothesis. It is also the case 
Figure 7. GDP response to the shadow policy rate

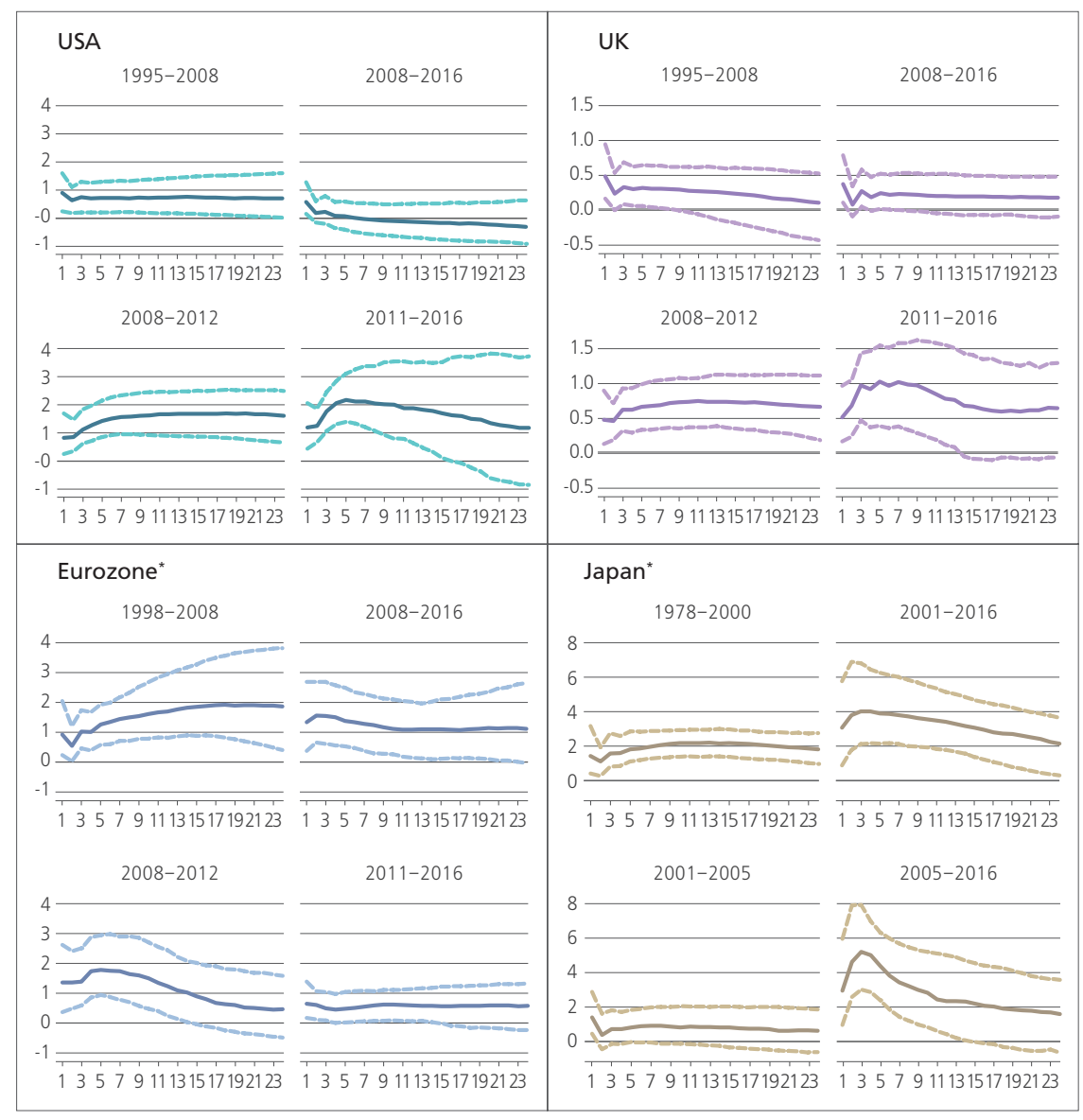

${ }^{*}$ Industrial production

The solid lines plot the median responses of log GDP to a 1 percentage point decrease of the shadow policy rate. The dashed lines plot the $68 \%$ Bayesian credible confidence set. The impulse response functions are computed using a Bayesian VAR with the sign restrictions described in the text and the following variables: $\log$ of GDP (industrial production for Japan and the eurozone), $\log$ CPI, long term interest rate (10 year bond rate), adjusted shadow policy rate, real equity prices, log effective exchange rate.

that the price effect is smaller after the financial crisis but, except for the Eurozone, there is no indication of decreasing effectiveness over the most recent sub-period, quite the contrary actually. This difference in results may be due to the fact that the European Central Bank was late in implementing unconventional policies. It could also reflect that the ECB shifted its policy in 2012 by adopting a more active stance ("whatever it takes"). Hence, the 2011 breakpoint may not be appropriate for the Eurozone. 
Figure 8. Price response to the shadow policy rate

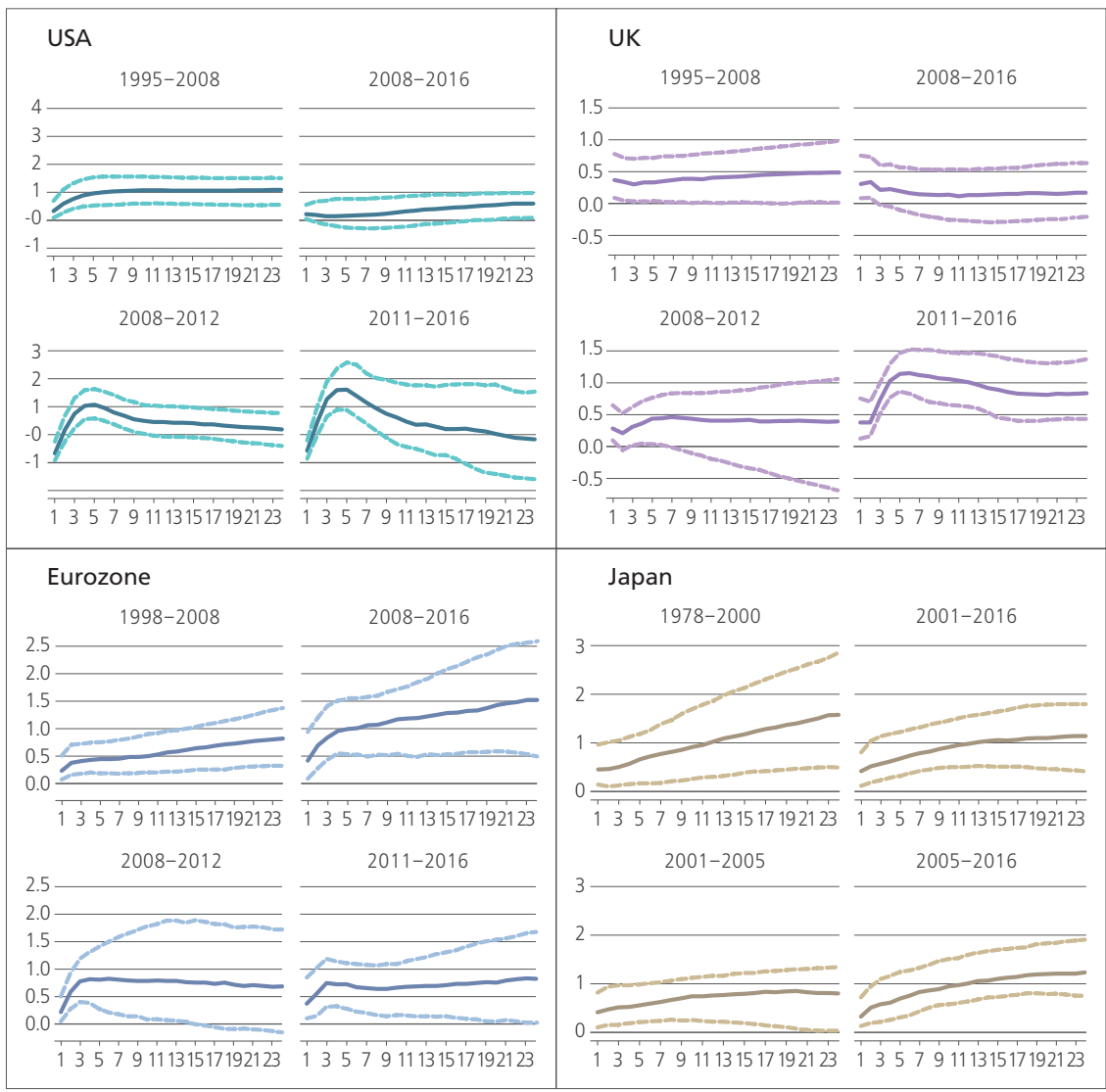

The solid lines plot the median responses of $\log$ CPI to a 1 percentage point decrease of the shadow policy rate. The dashed lines plot the 68\% Bayesian credible confidence set. The impulse response functions are computed using a Bayesian VAR with the sign restrictions described in the text and the following variables: log of GDP (industrial production for Japan and the eurozone), log CPI, long term interest rate (10 year bond rate), adjusted shadow policy rate, real equity prices, log effective exchange rate.

One feature, common to all cases except the Eurozone, is that GDP first rises strongly and then declines in the more recent sample, not in the earlier one. Table 1 provides the estimated impact at two different lags: when it is at its maximum and at lag $12^{23}$. This hump-shaped pattern is partly explained by the evolution of both the adjusted shadow rate itself and, to a lesser degree, of the effective exchange rate. There is no such evidence for the Eurozone, possibly due to the late shift of the policy stance, both in bringing the policy rate down to zero - and then below zero - and in adopting explicit QE.

\footnotetext{
${ }^{23}$ The results are similar to those reported by Weale and Wieladek (2015) with their second identification scheme, which we are using here.
} 
Table 1. Increase in GDP and CPI

\begin{tabular}{|c|c|c|c|c|c|c|c|c|}
\hline & \multicolumn{2}{|c|}{ US } & \multicolumn{2}{|c|}{ UK } & \multicolumn{2}{|c|}{ Eurozone } & \multicolumn{2}{|c|}{ Japan } \\
\hline & 2008-12 & 2011-16 & 2008-12 & 2011-16 & 2008-12 & 2011-16 & 2001-05 & 2005-16 \\
\hline \multicolumn{9}{|l|}{$\mathrm{GDP}^{1}$} \\
\hline Max & $0.21^{*}$ & $0.19^{\star}$ & $0.07^{\star}$ & $0.09^{\star}$ & $0.18^{\star}$ & $0.06^{\star}$ & 0.09 & $0.52^{\star}$ \\
\hline Lag 12 & $0.18^{\star}$ & $0.14^{*}$ & $0.05^{\star}$ & $0.08^{\star}$ & $0.12^{*}$ & $0.06^{*}$ & 0.08 & $0.23^{*}$ \\
\hline Lag max & 24 & 6 & 13 & 9 & 5 & 9 & 8 & 3 \\
\hline \multicolumn{9}{|l|}{ CPI } \\
\hline $\operatorname{Max}$ & $0.17^{\star}$ & $0.23^{\star}$ & $0.04^{*}$ & $0.11^{\star}$ & $0.08^{\star}$ & $0.08^{\star}$ & $0.09^{*}$ & $0.12^{\star}$ \\
\hline Lag 12 & $0.16^{*}$ & $0.12^{*}$ & $0.03^{*}$ & $0.10^{*}$ & $0.08^{*}$ & $0.07^{\star}$ & $0.08^{\star}$ & $0.10^{\star}$ \\
\hline Lag max & 17 & 5 & 5 & 6 & 6 & 3 & 20 & 24 \\
\hline
\end{tabular}

Notes: Maximum changes in $\log$ GDP and log CPI and changes at lag 12 following a 1 pP reduction of the adjusted shadow policy rate.

Taken together, these results suggest a nuanced view of the decreasing effectiveness hypothesis. There is little to support for the view that unconventional policies do not work or that their effectiveness has declined over the most recent period. On the other hand, there is some evidence that the effect is wearing out faster. This is associated with a more rapid reversal of the initial exchange depreciation and of the initial decline of the adjusted policy rate, possibly because markets see a declining room for maneuver, as discussed in Section 2. The weakening of the exchange rate channel may instead be due to the fact of joint expansionary policy stance of the largest central banks.

\subsection{The effect of large asset purchases (QE)}

We now move to our second indicator of unconventional monetary policy. For the US and the UK, we measure unconventional monetary policy with the announcements of asset purchases by the US Federal Reserve and the Bank of England. For Japan, instead, we use the balance sheet of the central banks because the long period of sporadic unconventional policies in Japan is not easily interpreted. As mentioned above we were unable to estimate the model for the European Central Bank.

Figure 9 presents the impulse response function of the exchange rate to an asset purchase of $1 \%$ of GDP. For the US and the UK, the three panels correspond respectively to the whole period of unconventional monetary policies, and to the first and second sub-periods. As before, these sub-periods have a 12 month overlap. For Japan, we present results for the periods before and after the financial crisis in 
Figure 9. Exchange rate response to $\mathrm{QE}$ announcements

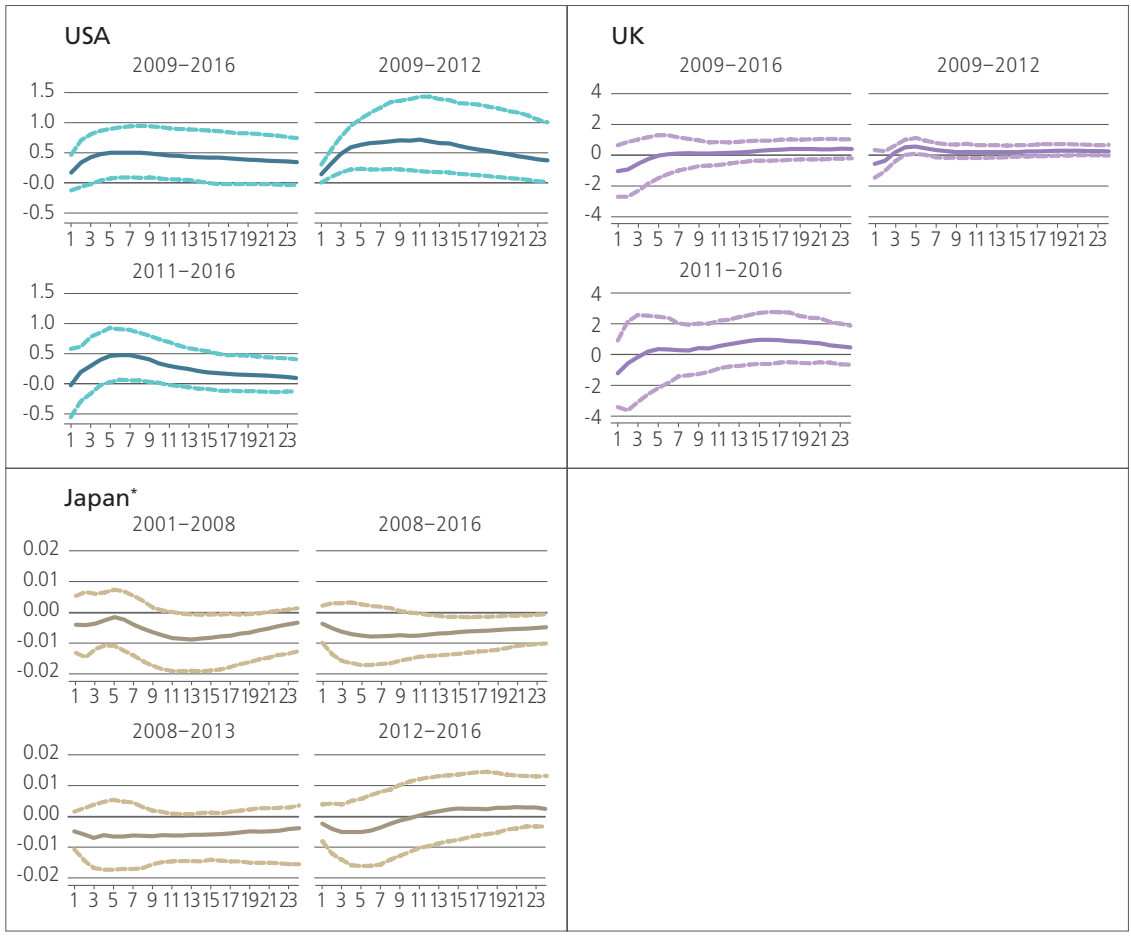

${ }^{*}$ Response to BoJ balance sheet

The solid lines plot the median responses of log effective exchange rate (an increase of the index is an appreciation) to an announcement of a 1 percent of GDP asset purchase (BoJ balance sheet in the case of Japan). The dashed lines plot the $68 \%$ Bayesian credible confidence set. The impulse response functions are computed using a Bayesian VAR with the sign restrictions described in the text and the following variables: log of GDP (industrial production for Japan), log CPI, long term interest rate (10 year bond rate), announcements of asset purchases over GDP (BoJ balance sheet over GDP for Japan), real equity prices, log effective exchange rate.

the top row, and to two equally sized and partially overlapping post-crisis sub-periods.

In the case of the US, the policy announcements lead to an appreciation of the effective exchange rate across all periods. These effects are not statistically significant, except for the early part where they also are somewhat stronger. This apparently surprising result can be seen as consistent with previous results reported in Section 3.4. The quoted literature indicates large effects on a wide range of financial asset prices, interpreted as an indication that QE was instrumental in alleviating market dysfunctions in the wake of the financial crisis. Of interest is the contrast with Figure 6, which indicates that cuts in the adjusted shadow rate led to an exchange rate depreciation. The shadow policy rate measures the policy rate that would be observed in the absence of an effective lower bound given the slope 
Figure 10. GDP response to $\mathrm{QE}$ announcements

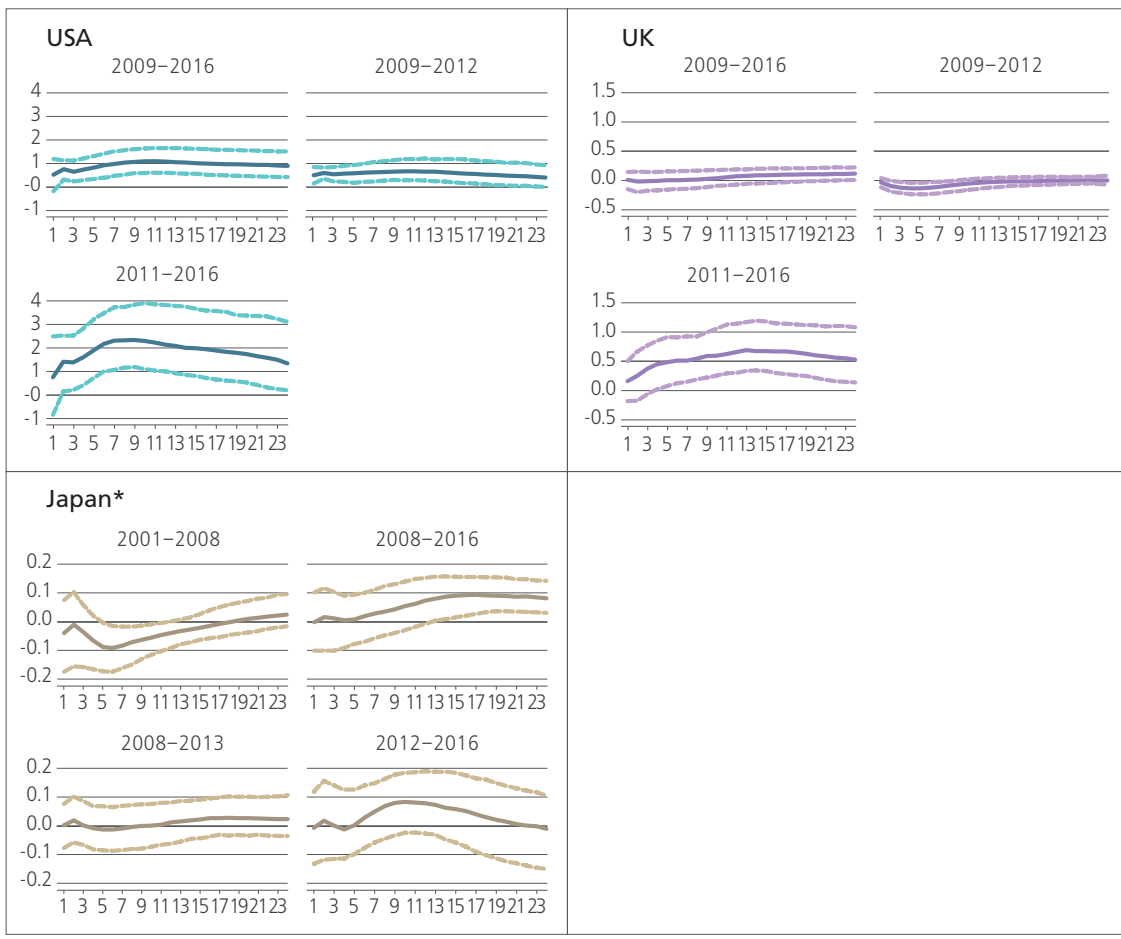

${ }^{*}$ Response of industrial production to BoJ balance sheet

The solid lines plot the median responses of log GDP to an announcement of a 1 percent of GDP asset purchase (BoJ balance sheet in the case of Japan). The dashed lines plot the $68 \%$ Bayesian credible confidence set. The impulse response functions are computed using a Bayesian VAR with the sign restrictions described in the text and the following variables: log of GDP (industrial production for Japan), log CPI, long term interest rate (10 year bond rate), announcements of asset purchases over GDP (BoJ balance sheet over GDP for Japan), real equity prices, log effective exchange rate.

of the yield curve. The adjusted rate incorporates all policy announcements. Therefore it differs from asset purchase announcements as it incorporates how all policy announcements affect the slope of the yield curve possibly through portfolio reallocation and expectations on future policy actions. This suggests that lower policy interest rates alone, no matter what their levels - positive or negative - are, produce standard effects on the exchange rate. However, the expansion of central bank liquidity may lead to an appreciation if its main effect is to reduce financial market disruptions. Since QE can combine both characteristics, it is not surprising perhaps to see in Figure 9 that the overall impact on British and Japanese exchange rate is not statistically different from zero.

The estimated output and price effects of QE - announcements in the case of the US and UK, actual purchases in the case of Japan — are displayed in Figures 10 
Figure 11. Price response to QE announcements

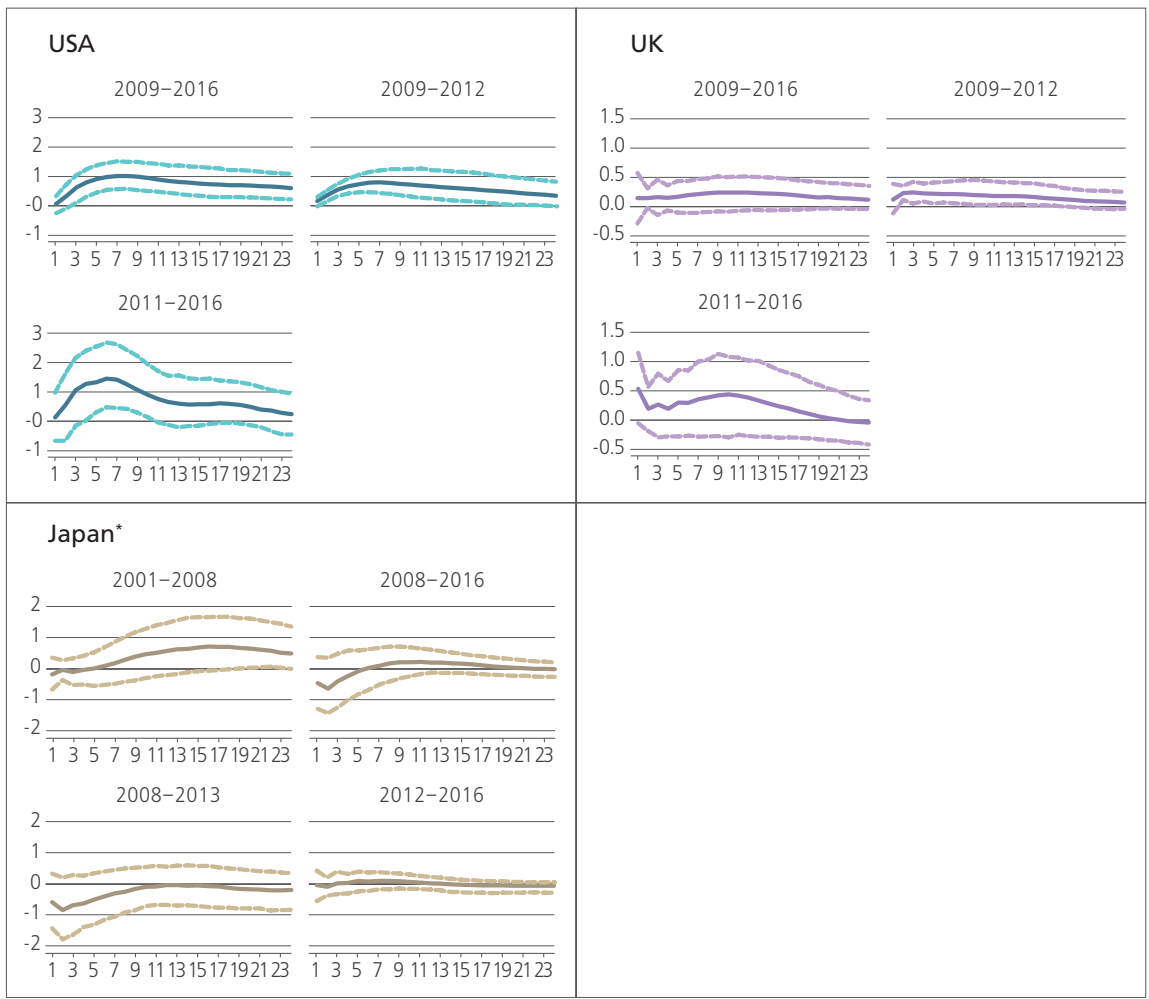

${ }^{*}$ Response to BoJ balance sheet

The solid lines plot the median responses of $\log$ CPI to an announcement of a 1 percent of GDP asset purchase (BoJ balance sheet in the case of Japan). The dashed lines plot the $68 \%$ Bayesian credible confidence set. The impulse response functions are computed using a Bayesian VAR with the sign restrictions described in the text and the following variables: $\log$ of GDP (industrial production for Japan), log CPI, long term interest rate (10 year bond rate), announcements of asset purchases over GDP (BoJ balance sheet over GDP for Japan), real equity prices, log effective exchange rate.

and 11. In the US and UK, the output and price effects are larger in the most recent period, thus apparently running against the decreasing effect hypothesis. Yet, it must be noted that these effects are less precisely estimated and not always significant. The fact that these effects are mostly significant in the early period of unconventional policies confirms the previous observation that the liquidity effect of QE works in the presence of financial market disruptions, not as a monetary policy instrument. In Japan, the effects are not significant, even though the estimates are larger over the most recent period when QE was enacted very explicitly.

We next focus on comparisons with Figures 7 and 8. In line with the reasoning above, we interpret the difference between the adjusted shadow rate and QE as 
representing the effects of all other unconventional policies, chiefly policy interest rate cuts until the effective lower bound is reached and central bank signals afterwards. It is not surprising, therefore that the impulse response functions shown in Figures 10 and 11 display smaller output and price effects in the US and $\mathrm{UK}$, and that the differences are larger for the early period when the policy rates were being cut. In Japan, difference is also larger over the most recent sub-period, an indication that the change is policy in 2013 made a difference.

\section{Conclusions}

Three main conclusions emerge. First, unconventional policies work. Second they work less well than conventional policies. Third, there is limited evidence that their effectiveness has declined over time. Whatever evidence exists, it may be a confirmation of earlier studies that find these policies to be helpful in the presence of financial market disruptions, less so when the markets have recovered.

Table 2. Evidence on decreasing effectiveness ${ }^{a}$

\begin{tabular}{|c|c|c|c|c|}
\hline \multicolumn{5}{|c|}{ Measure of unconventional policy } \\
\hline & \multicolumn{2}{|c|}{ Adjusted Shadow Policy Rate } & \multicolumn{2}{|c|}{ QE Announcements } \\
\hline \multicolumn{5}{|c|}{ Econometric approach } \\
\hline & $\begin{array}{c}\text { Local } \\
\text { projections }\end{array}$ & BVAR & $\begin{array}{c}\text { Local } \\
\text { projections }\end{array}$ & BVAR \\
\hline US-GDP & yes & yes $^{b}$ & no & no \\
\hline US-CPI & yes & yes $^{b}$ & mixed & yes $^{b}$ \\
\hline UK-GDP & yes & yes $^{b}$ & no & no \\
\hline UK-CPI & yes & no & yes & yes $^{b}$ \\
\hline EZ-GDP & yes & mixed & no & $\mathrm{n} / \mathrm{a}$ \\
\hline EZ-CPI & yes & mixed & no & $\mathrm{n} / \mathrm{a}$ \\
\hline Japan-GDP & yes & no & $\mathrm{n} / \mathrm{a}$ & no \\
\hline Japan-CPI & yes & no & $\mathrm{n} / \mathrm{a}$ & no \\
\hline
\end{tabular}

At the methodological level, we find that the results are sensitive to the way unconventional policies are measured, to the criterion (GDP or CPI), and to the econometric approach. Table 2 summarizes our results, whether we measure policy with the adjusted shadow policy rate with QE announcements or actions, and whether we use BVARs or local projection as indicated in the Appendix. When we use the adjusted shadow policy rate our evidence is broadly consistent with decreasing effectiveness both when we use local projections and Bayesian VARs. 
However, when we use QE announcements, we rarely find evidence that is consistent with the decreasing effectiveness hypothesis (with the exception of a price effect for the US and the UK which, however, does not appear to be robust across estimation methodologies).

A yes/no assessment may be too rough to do justice to the overall profile of impulse response functions, however. We need to look at the whole horizon. A careful analysis of these profiles suggest that during the more recent period the impact of unconventional policies has not declined, or has even increased in several instances, but that the effect wears out fast.

We also need to keep in mind that the impulse response functions look the effects of a one-off effect of a shock to the chosen measure of unconventional policy. It matters a great deal how this measure evolves over time. A key argument in favor of the decreasing effectiveness hypothesis is that the policy space is shrinking when the policy interest rate reaches its effective lower bound and when the balance sheet has already been considerably enlarged. We find some evidence that the shadow policy rate, which includes market expectations, tends to reverse faster over the most recent period. This pattern is mirrored in the evolution of the exchange rate, a potentially important channel of monetary policy.

Many caveats apply. First, it may be too early to assess the decreasing effectiveness hypothesis. Facing short samples, we have been led to use partially overlapping subperiods, which works against finding supporting evidence. In addition, the limited sample size leads to large standard errors. Furthermore, macroeconomic phenomena are low frequency events; using monthly data increases the sample size but does not erase the fact that we do not have much perspective. Second, we do not test the hypothesis formally. We simply compare visually the economic responses to policy actions. Third, in line with much of the literature, we look at the responses of GDP and CPI levels, not at their growth rates. This is a natural next step. Fourth, some other variables may need to be included. We have experimented with a measure of financial market volatility (the VIX index) and the results did not change significantly. Finally, the sensitivity of results to the measure of policy and to the econometric approach calls for much more experimentation.

Appendix is available at: www.cbr.ru/money-and-finance

\section{References}

Altavilla, C. and Giannone, D. (2015). The Effectiveness of Unconventional Monetary Policy Measures: Evidence from Survey Data, Staff Report 752, Federal Reserve Bank of New York.

Arteta, C., Kose, M., Stocker, M. and Taskin, T. (2016). Negative Interest Rate Policies: Sources and Implications, Discussion Paper DP11433, CEPR, London.

Armstrong, A., Caselli, F., Chadha, J. and den Haan, W. (2015). Risk-Sharing and the Effectiveness of the ECB's Quantitative Easing Programme, VoxEU, CEPR, 23 October. 
Ball, L. and Sandeep, M. (2011). Inflation Dynamics and the Great Recession, Brookings Papers on Economic Activity, Spring: pp. 337-381.

Ball, L., Gagnon, J., Honohan, P. and Krogstrup, S. (2016). What Else Can Central Banks Do? Geneva Report 18, CEPR and ICMB.

Barnichon, R., Matthes, C. and Ziegenbein, A. (2016). Assessing the Non-Linear Effects of Credit Market Shocks, Discussion Paper 11410, CEPR.

Bauer, M. and Rudebusch, G. (2014). The Signaling Channel for Federal Reserve Bond Purchases, International Journal of Central Banking, 10(3), pp. 233-289.

Baumeister, Ch. and Benati, L. (2013). Recession: Estimating the Macroeconomic Effects of a Spread Compression at the Zero Lower Bound. International Journal of Central Banking, 9(2), pp. 165-212.

Bean, C., Broda, C., Takatoshi, I. and Kroszner, R.(2015). Low for Long? Causes and Consequences of Persistently Low Interest Rates. Geneva Reports on the World Economy 17, CEPR, London and ICMB, Geneva.

Bech, M. and Malkhozov, A. (2016). How Have Central Banks Implemented Negative Policy Rates? BIS Quarterly Review, March 2016, pp. 31-44.

Bernanke, B. (2016). What Tools Does the fed Have Left? The Brookings Institution, Washington DC. Available at:

http://www.brookings.edu/blogs/ben-bernanke/posts/2016/03/18-negative-interest-rates

Bernanke, B. and Gertler, M. (1995). Inside the Black Box: The Credit Channel of Monetary Policy Transmission. Journal of Economic Perspectives, 9 (Fall), pp. 27-48.

Bernanke, B., Reinhart, V. and Sack, B. (2004). Monetary Policy Alternatives at the Zero Bound: An Empirical Assessment. Brookings Papers on Economic Activity, 35(2), pp. 1-100.

Black, F. (1995). Interest Rates as Options. The Journal of Finance, Vol. 50(5), pp. 1371-1376.

Blanchard, O. (2016a). The State of Advanced Economies and Related Policy Debates: A Fall 2016 Assessment, Policy Brief 16-14, Peterson Institute for International Economics, Washington, DC.

Blanchard, O. (2016b). The US Phillips Curve: Back to the 60s? Policy Brief 16-1, Peterson Institute for International Economics, Washington, DC.

Borio, C. and Zabai, A. (2016). Unconventional Monetary Policies: A Re-Appraisal, unpublished paper, BIS.

Brunnermeier, M. and Koby, Y. (2016). The "Reversal Rate": Effective Lower Bound on Monetary Policy, paper presented at the BIS research network meeting, 14 March.

Caballero, R., Farhi, E. and Gourinchas, P.-O. (2015). Global Imbalances and Currency Wars at the ZLB, NBER Working Paper No. 21670.

Carpenter, S., Demiralp, S. and Eisenschmidt, J. (2013). The Effectiveness of the NonStandard Policy Measures during the Financial Crises: The Experiences of the Federal Reserve and the European Central Bank, Working Paper 1562, ECB.

Christensen, J. and Rudebusch, G. (2015). Estimating Shadow-Rate Term Structure Models with Near-Zero Yields. Journal of Financial Econometrics, 13(2), pp. 226-259.

Churm, R., Joyce, M., Kapetanios, G. and Theodoridis, K. (2015). Unconventional Monetary Policies and the Macroeconomy: The Impact of the United Kingdom's QE2 and Funding for Lending Scheme, Staff Working Paper 542. London: Bank of England. 
Cohen, G., Lee, S. and Stebinovs, V. (2016). Limits to Monetary Policy Transmission at the Zero Lower Bound and Beyond: the Role of Nonbanks, unpublished, Board of Governors of the Federal Reserve System.

Coeuré, B. (2016). Assessing the Implications of Negative Interest Rates, speech at the Yale Financial Crisis Forum, Yale School of Management, New Haven, 28 July.

Curdia, V. and Woodford, M. (2011). The Central-Bank Balance Sheet as an Instrument of Monetary Policy, Journal of Monetary Economics, 58(1), pp. 54-79.

Darracq-Paries, M. and De Santis, R. (2013). A Non-Standard Monetary Policy Shock The ECB's 3-Year LTROs And the Shift in Credit Supply, Working Paper 1508, ECB.

Demertzis, M. and Wolff, G. (2016). The Effectiveness Of The European Central Bank's Asset Purchase Programme, Bruegel Economic Contribution 10, BRUEGEL.

Den Haan, W. (ed.) (2016). Quantitative Easing, VoxEU ebook.

Disyatat, P. (2010). The Bank Lending Channel Revisited, BIS Working Paper 297.

Draghi, M. (2016). Delivering a Symmetric Mandate with Asymmetric Tools: Monetary Policy in a Context of Low Interest Rates, speech at the ceremony to mark the 200th anniversary of the Oesterreichische Nationalbank, ECB, 2 June.

Eggertsson, G., Mehrotra, N. and Summers, L. (2016). Secular Stagnation in the Open Economy, American Economics Review, Papers and Proceedings, 106(5), pp. 503-507.

Eichengreen, B. and Panizza, U. (2016). A surplus of ambition: can Europe rely on large primary surpluses to solve its debt problem? Economic Policy, 31(85), pp. 5-49.

Engen, E., Laubach, T. and Reifschneider, D. (2015). The Macroeconomic Effects of the Federal Reserve's Unconventional Monetary Policies, Finance and Economic Discussion Series 2015-005, Board of Governors of the Federal Reserve System. Available at: http://dx.doi.org/10.17016/FEDS.2015.005

Foerster, A. (2014). The Asymmetric Effects of Uncertainty, Economic Review, Federal Reserve Bank of Kansas City, pp. 5-26.

Fratzscher, M., Duca, M. and Straub, R. (2014). ECB Unconventional Monetary Policy Actions: Market Impact, international Spillovers and Transmission Channels, presented at the 15th Jacques Polak Annual Research Conference.

Friedman, M. and Schwartz, A. (1963). A Monetary History of the United States, Princeton: Princeton University Press.

Gagnon, J., Raskin, M., Remache, J. and Sackb, B. (2011). The Financial Market Effects of the Federal Reserve's Large-Scale Asset Purchases, International Journal of Central Banking, 7(1), pp. 3-43.

Garcia Pascual, A. and Wieladek, T. (2016). The European Central Bank's QE: A New Hope. Discussion Paper 11309, CEPR.

Goodhart, Ch. and Ashworth, J. (2013). QE: A Successful Start May Be Running Into Diminishing Returns, Oxford Review of Economic Policy, 28 (4), pp. 640-670.

Haldane, A., Roberts-Sklar, M., Wieladek, T. and Young, Ch. (2016). QE: the story so far. Bank of England Staff Working Paper No. 624

Hung, G. (2016). Unconventional Monetary Policy and Bank Lending. Unpublished, International Monetary Fund.

International Monetary Fund (2015). Global Financial Stability Report, October, Washington DC

Jordà, Ò. (2005). Estimation and Inference of Impulse Responses by Local Projections. American Economic Review, 95(1), pp.161-182. 
Kapetanios, G., Mumtaz, H., Stevens, I. and Theodoridis, K. (2012). Assessing The Economy-Wide Effects of Quantitative Easing. The Economic Journal, 122, pp. 316-347.

Kiley, M. (2015). Low Inflation in the United States: A Summary of Recent Research. FEDS Notes, Federal Reserve Board,

Lenza, M., Pill, H. and Reichlin, L. (2010). Monetary Policy in Exceptional Times. Economic Policy, 25(62), pp. 295-339.

Krippner, L. (2013). A tractable framework for zero lower bound Gaussian term structure models. Discussion Paper, Reserve Bank of New Zealand, 2013/02.

Krishnamurthy, A. and Vissing-Jorgensen, A. (2013) The Ins and Outs of Large Scale Asset Purchases. Kansas City Federal Reserve Symposium on Global Dimensions of Unconventional Monetary Policy.

Leeper, E., Sims, Ch. and Zha, T. (1996). What Does Monetary Policy Do? Brookings Papers on Economic Activity, 27(2), pp. 1-78.

Lewbel, A. (2010). Using Heteroscedasticity to Identify and Estimate Mismeasured and Endogenous Regressor Models. Journal of Business \& Economic Statistics, 30(1), pp. 67-80.

Lombardi, M. and Zhu, F. (2014). A shadow policy rate to calibrate US monetary policy at the zero lower bound. BIS Working Papers No 452.

Nishimura, K. (2016) Central Banks Face Monetary Policy Exhaustion. Nikkei Asian Review, September. Available at:

http://asia.nikkei.com/Viewpoints/Viewpoints/Kiyohiko-G.-Nishimura-Centralbanks-face-monetary-policy-exhaustion

Oakley, D. (2016). Quantitative Exhaustion Smothers Markets. The Financial Times, 19 June. Available at: http://www.ft.com/cms/s/0/0aff1e16-32d9-11e6-bda0-04585c31b153. html\#axzz4FPnO8uh8

Orphanides, A. and Wieland, V. (2000). Efficient Monetary Policy Design near Price Stability, Journal of the Japanese and International Economies, 14, pp. 327-365.

Rigobon, R. (2003). Identification Through Heteroskedasticity. The Review of Economics and Statistics, 85(4), pp. 777-792.

Roubini, N. (2013). Ten QE Questions. Project Syndicate, 28 February.

Santor, E. and Suchanek, L. (2016). A New Era of Central Banking: Unconventional Monetary Policies. Bank of Canada Review, Spring, pp. 29-42.

Ueda, K. (2012). The Effectiveness of Non-Traditional Monetary Policy Measures: The Case of the Bank of Japan, The Japanese Economic Review, 63(1), pp. 1-22.

Uhlig, H. (2005). What are the effects of monetary policy on output? Results from an agnostic identification procedure. Journal of Monetary Economics, 52, pp. 381-419

Vitale, G. (2016). Financial distress regimes and business investment in the euro area. Mimeo, European Central Bank.

Weale, M. and Wieladek, T. (2015). What Are the Macroeconomic Effects of Asset Purchases. Discussion Paper 10495, CEPR.

World Bank (2015). Negative Interest Rates in Europe: A Glance at Their Causes and Implications", Global Economic Prospects, June, pp. 3-9.

Wu, J. and Xia, F. (2016). Measuring the Macroeconomic Impact of Monetary Policy at the Zero Lower Bound. Journal of Money, Credit and Banking 48 (2-3), pp. 253-291. 